\title{
Interaction between root exudates and rhizosphere microorganisms facilitates the expansion of poisonous plant species in degraded grassland
}

\section{Wenyin Wang}

Lanzhou University School Of Life Sciences

Tianhua Jia

Lanzhou University School Of Life Sciences

Tianyun Qi

Lanzhou University School Of Life Sciences

\section{Shanshan Li}

Lanzhou University College of Pastoral Agriculture Science and Technology

\section{Degen A.Allan}

Ben-Gurion university of the Negev Beer Sheva Wyler Department of Dryland Agriculture, Blaustein Institutes for Desert Research

\section{Jin Han}

Lanzhou University School Of Life Sciences

\section{Yanfu Bai}

Lanzhou University School Of Life Sciences

\section{Tao Zhang}

Lanzhou University School Of Life Sciences

\section{Shuai Qi}

Lanzhou University School Of Life Sciences

\section{Mei Huang}

Lanzhou University School Of Life Sciences

\section{Zihao Li}

Lanzhou University School Of Life Sciences

\section{Jianxin Jiao}

Lanzhou University College of Pastoral Agriculture Science and Technology

\section{Zhanhuan Shang ( $\square$ shangzhh@lzu.edu.cn )}

Lanzhou University School Of Life Sciences https://orcid.org/0000-0002-6069-4708

\section{Research}


Keywords: poisonous plants expansion, root exudation, rhizosphere microorganisms, convergence, degraded grassland, WGCNA network

Posted Date: February 11th, 2021

DOI: https://doi.org/10.21203/rs.3.rs-208803/v1

License: (c) (1) This work is licensed under a Creative Commons Attribution 4.0 International License. Read Full License 


\section{Abstract \\ Background}

The interaction between rhizosphere microorganisms and rhizosphere exudates is considered a 'novel weapon' for poisonous plants' colonization, but the relationship between them in facilitating the expansion of poisonous plants in degraded or barren land is poorly understood. We examined this relationship in different degradation levels of alpine grasslands on the Tibetan plateau (3,700 $\mathrm{m}$ a.s.l) by determining the composition of root exudates, soil physical and chemical properties, rhizosphere microbial diversity and carbon metabolism of the main poisonous and non-poisonous plant species.

\section{Results}

Soil nutrients, including total organic carbon, total nitrogen and available phosphorous, diversity of microorganisms and microbial carbon metabolism were greater in the rhizosphere of poisonous than in non-poisonous plant species $(P<0.05)$. The distribution of bacteria and root exudates were plant species specific. Soil microbial communities were affected by habitat and plant species in degraded grassland, and more so for bacteria than fungi. The cell growth and death pathway for the poisonous species Ligularia virgaurea was greater than for other poisonous species $(P<0.05)$, and the difference increased with an increase in grassland degradation and a decrease in soil nutrients $(P<0.05)$, which could explain how $L$. virgaurea became the dominant poisonous species in degraded alpine grassland. The roots of $L$. virgaurea exudated such compounds as alkaloids, lupinic acid, terpenes, artemisinin, and coumarin, which were correlated positively with different bacteria in different habitats.

\section{Conclusion}

It was concluded that poisonous plant species adapted to degraded grassland through the interaction of root exudates and rhizosphere microorganisms, which facilitated their expansion in degraded alpine grassland.

\section{Introduction}

Root exudates of plants and rhizosphere microorganisms alter the soil environment to aid plants compete for nutrients and to allow their offspring to be more viable $[1,2,3,4,5]$. The rhizosphere contains a large number of microorganisms, which participate in regulating the physiology and morphology of plants, in enhancing the growth of plants by producing phyto-hormones, and in protecting plants against pathogens $[4,6]$. In addition to the carbon and nitrogen substrates that represent microbial growth, root compounds have multiple effects on inter-root microbes by acting as signaling agents, inducers, stimulants, inhibitors and repellents [7], thereby regulating soil conditions for themselves and other plants, including their own offspring. The interaction between rhizosphere microorganisms and 
rhizosphere exudates is considered a 'novel weapon' of poisonous plant species to adapt to degraded grassland and may be an important mechanism in allowing them to spread $[8,9,10,11,12,13]$.

Roots of plants typically exude $30 \%-40 \%$ of carbon fixed by photosynthesis [14]. The exudate contains bio-active molecules, primary metabolites such as sugars, amino acids, and carboxylic acids, and secondary metabolites such as terpenoids, which can alter the soil microbiome $[15,16,17]$. Root exudate creates a favorable soil environment for the plant $[4,12,18]$ by mediating the metabolism of rhizosphere microorganisms to alter the soil pH and nutrient content and turnover $[1,3,10,19]$. The exudate is linked with plant diversity and soil microorganisms [20], as exudate of some species, such as poisonous plants or weeds (e.g. Stellera chamaejasme, Colchicum autumnale) can affect other plant species $[11,21,22,23$, 24].

The spreading of poisonous plants in degraded grassland is a global problem and is a result, at least in part, of global warming and over-grazing by livestock [25]. The problem is particularly acute on the Tibetan plateau $[26,27,28]$, which comprises approximately $77 \%$ of the $4504 \cdot 10^{4}$ ha of the degraded grassland in China [29]. In the grassland ecosystem, native poisonous plant species increase and expand aggressively with degradation and barren soil and gradually become the dominant species in the community (Additional file 1: Figure S1). The expansion of poisonous plant species is not only confined to the natural degraded grassland, but is also evident in sown grassland on the Tibetan plateau $[30,31$, 32, 33] (Additional file 1: Figure S1).

In the grassland ecosystem, studies on poisonous plant species have focused on their high nutrient use efficiency and strong competitive ability when compared to other plant species [27, 28, 34], allelopathy [11], and morphological and physiological traits [35]. Poisonous plant species are more efficient in utilizing $\mathrm{N}$ in poor nutrient soil than sedges and grasses, which may have been their survival mechanism in alpine grassland [28]. However, during the spreading of poisonous plants, self-reinforcing is a key driving force in degraded grassland $[4,8,36]$, with the interaction of root exudates and rhizosphere microorganisms a key factor in the process $[4,24,37]$. We hypothesized that the exudate from roots of poisonous plant species contain more compounds for specific microorganisms to promote self-growth than non-poisonous plant species. To test this hypothesis, we analyzed the specificity of root exudates and rhizosphere microorganisms in poisonous and non-poisonous plant species in alpine grasslands of different levels of degradation.

\section{Material And Methods}

\subsection{Study sites and design}

The study site was located at the headwater region of the Yellow River in the eastern Tibetan plateau in Marqin County, Guoluo Tibetan Autonomous Prefecture, Qinghai Province $\left(34^{\circ} 28^{\prime} \mathrm{N}, 100^{\circ} 12^{\prime} \mathrm{E}\right)$ (Additional file 1: Figure S1). The site is $1.5 \mathrm{~km}^{2}$ in size, approximately $3720 \mathrm{~m}$ a.s.l., and has a highland continental climate with no absolute frost-free days. Annually, average temperature is $-0.1-1.2^{\circ} \mathrm{C}$, average 
precipitation is $463-602 \mathrm{~mm}$, evaporation is approximately $1460 \mathrm{~mm}$, and total sunshine is $2272-2632$ h. The grassland type is alpine meadow $[32,37,38]$. The dominant plant species of native grassland are Kobresia pygmaea, Stipa spp. and Kobresia humilis. Traditionally, the site is used for winter grazing of yak and sheep from December to March. We previously studied grassland degradation processes, soil nutrients and vegetation regeneration at the same site $[32,37,38,39]$.

The study site included grasslands at different levels of degradation. In the process of degradation, small bare patches form, and poisonous plants appear in the patch [40]. With the spreading of the poisonous plants, the bare patch enlarges [40], the sward layer disappears and often only poisonous plants occupy the degraded grassland. Heavily degraded grassland is known as 'bare land' and the level of degradation is based on the ratio of bare land to living sward $[33,40]$. Lightly $(L)$, moderately $(M)$ and heavily $(H)$ degraded native grassland, and degraded sown grassland (S) were selected (Additional file 1: Appendix S1). The degraded sown grassland was restored 'bare land' (heavy degraded grassland) more than 10 years ago, but became degraded again with the invasion and spreading of poisonous plants [38, 39].

\subsection{Vegetation survey and root, soil sampling}

Field sampling was done in August, 2017, and August, 2018, when alpine plants reached peak growth. Four sampling plots at each level of degradation were selected randomly. The distance between any two plots was greater than $100 \mathrm{~m}$, which exceeded the spatial dependence of microbial variables [41], and thus the samples in each plot were independent. Three sub-plots, with more than $20 \mathrm{~m}$ between any two, were selected in each plot. Fifteen random quadrats $(50 \mathrm{~cm} \times 50 \mathrm{~cm})$ in each sub-plot were selected to record plant cover, height and composition [42]. In some cases, there were the same poisonous plant species in different habitats (different levels of degradation) and the same habitat had different poisonous plant species.

After the vegetation survey, some plants with high frequency and coverage were selected (Additional file 1: Table S1). Rhizosphere soil was collected for Morina kokonorica in L; Aconitum pendulum, Ajuga Iupulina, Euphorbia fisheriana, Ligularia virgaurea, and M. kokonorica in M; A. Iupulina, E. fisheriana, Sphallerocarpus gracilis, L. virgaurea, M. kokonorica, Artemisia dubia, Artemisia nanschanica, and $A$. pendulum in $\mathrm{H}$; and, L. virgaurea, M. kokonorica, Oxytropis ochrocephala, S. gracilis, and Pedicularis kansuensis in S (Additional file 1: Figure S1; Additional file 1: Table S1). In addition, bulk (nonrhizosphere) soil was collected in each habitat as control. In total 66 samples (3 replicates) in 4 habitats were collected in 2017, 6 in L, 18 in M, 27 in H and 15 in S. Rhizosphere and bulk soils were used to determine the microbial community and microbial carbon metabolism. Rhizosphere soil and root exudation were collected from L. virgaurea, M. kokonorica,and Kobresia pygmaea in L; A. pendulum and L. virgaurea in $\mathrm{M}$; L. virgaurea in $\mathrm{H}$; and, P. kansuensis, Elymus nutans and low ( $<120$ plants $\left./ \mathrm{m}^{2}\right)$, medium (120-240 plants $/ \mathrm{m}^{2}$ ) and high (>360 plants $/ \mathrm{m}^{2}$ ) densities of L. virgaurea in S (Additional file 1: Figure S1; Additional file 1: Additional file 1: Table S1). In total 22 samples (3 replicates) in 4 habitats were collected in 2018, 9 in L, 6 in M, 3 in $\mathrm{H}$ and 15 in S. The rhizosphere soil was used to determine the microbial community. 
The rhizosphere soil was collected as described by Edwards et al. [43]. In brief, the whole plant was dug up with a shovel, the soil around the root was removed by shaking, and the soil within $2 \mathrm{~mm}$ of the root surface was shaken into a sterile ziplock bag and mixed well. Roots and litter were removed manually, and then a small amount of soil was placed into a $3 \mathrm{~mL}$ sterile centrifuge tube, which was kept in liquid nitrogen, for determining the diversity of the soil microbial community. The remaining soil was divided into two parts: one was brought to the laboratory with an ice pack, and refrigerated at $4{ }^{\circ} \mathrm{C}$ for determination of soil microbial carbon metabolism and the other was air-dried and then put through a 2$\mathrm{mm}$ sieve. Nine soil core samples $(3.5 \mathrm{~cm}$ in diameter) at a depth of $0-10 \mathrm{~cm}$ were collected at each sampling plot, mixed and homogenized, and three core soil samples were combined into one composite sample. This soil sample was termed 'bulk soil' and was free from the influence of plants. Fifteen individual plants of each poisonous species were collected, the roots were rinsed with distilled water and then immersed in $500 \mathrm{~mL}$ distilled water for $10 \mathrm{~h}$, and all extraction was placed into a $100 \mathrm{~mL}$ plastic bottle. The extraction was refrigerated at $4{ }^{\circ} \mathrm{C}$, and then the root exudates were measured as soon as possible.

\subsection{Soil chemical properties}

Soil pH was measured using a pH meter (Sartorius PB-10, Goettingen, Germany) in a 1:2.5 soil:water solution (w/v). Soil total $\mathrm{N}(\mathrm{TN})$ was determined by the micro-Kjeldahl method with digestion in $\mathrm{H}_{2} \mathrm{SO}_{4}$ followed by steam distillation. Soil total phosphorous (TP) was digested with $\mathrm{HF}-\mathrm{HClO}_{4}$ and ammonium and nitrate were extracted by $2 \mathrm{~mol} / \mathrm{L}$ potassium chloride. TN, TP, ammonium and nitrate were measured with flow injection analyzer (FIA star5000 Analyzer, Höganäs, Sweden). Soil total organic carbon (TOC) content was determined by wet digestion using the potassium dichromate method and available P (AP) was determined using the molybdenum-blue method by UV spectrophotometer (HITACHI U-2910, Tokyo, Japan) after extraction with sodium bicarbonate.

\subsection{Microbial community sequencing and data processing}

To extract DNA from soil samples, the E.Z.N.A. Soil DNA Kit (Omega Bio-tek, Norcross, GA, U.S.) was used according to the manufacturer's protocol. Illumina sequencing was performed by amplifying the V4/V5 region of the bacterial $16 \mathrm{~S}$ rRNA gene using individually bar-coded forward primers $515 \mathrm{~F}$ (5'GTGCCAGCMGCCGCGG-3') and reverse primers 907R (5'-CCGTCAATTCMTTTRAGTTT-3') and ITS1 region of ITS using individually bar-coded forward primers ITS1F (5'-CTTGGTCATTTAGAGGAAGTAA-3') and reverse primers ITS1R (5'-GCTGCGTTCTTCATCGATGC-3'). PCR reactions were done in triplicate $20 \mu \mathrm{L}$ mixtures containing $4 \mu \mathrm{L}$ of $5 \times$ FastPfu Buffer, $2 \mu \mathrm{L}$ of $2.5 \mathrm{mM}$ dNTPs, $0.8 \mu \mathrm{L}$ of each primer $(5 \mu \mathrm{M}), 0.4$ $\mu \mathrm{L}$ of FastPfu Polymerase, and $10 \mathrm{ng}$ of template DNA. Amplicons were extracted from $2 \%$ agarose gels, purified according to the manufacturer's instructions and quantified using QuantiFluor ${ }^{\mathrm{Tm}}$-ST (Promega, U.S.). The PCR conditions were as follows: $95^{\circ} \mathrm{C}$ for $2 \mathrm{~min}$, followed by 25 cycles at $95^{\circ} \mathrm{C}$ for $30 \mathrm{~s}, 55^{\circ} \mathrm{C}$ for $30 \mathrm{~s}$, and $72^{\circ} \mathrm{C}$ for $30 \mathrm{~s}$ and a final extension at $72^{\circ} \mathrm{C}$ for $5 \mathrm{~min}$. Purified PCR products were quantified by Qubit ${ }^{\circledR 3}$.0 (Life Invitrogen). The pooled DNA product was used to construct an Illumina Pair-End library following Illumina's genomic DNA library preparation procedure. The amplicon library was pairedend sequenced on an Illumina HiSeq 2500 according to standard protocols. 
Raw fastq files were demultiplexed and quality-filtered using QIIME (version 1.17). Operational Units (OTUs) were clustered with $97 \%$ similarity cutoff using usearch and chimeric sequences were identified and removed by denovo. The rarefaction curves of alpha diversity index were drawn by QIIME. The phylogenetic affiliation of each 16S rRNA gene sequence was analyzed by sortmerna against the Greengene (16S rRNA) database. After classification, the OTU abundance table was obtained according to the number of sequences in each OTU, and subsequent analysis was done according to the OTU abundance table [44].

\subsection{Microbial carbon metabolism assay}

Soil microbial carbon source metabolism was determined using Biolog-Eco plates. Ten g soil were placed in a $250 \mathrm{~mL}$ conical bottle, $90 \mathrm{~mL}$ sterile saline $(0.85 \% \mathrm{NaCl}$ solution) were added, the conical bottle was sealed with sealing film, shaken at $200 \mathrm{r} / \mathrm{min}$ at $25^{\circ} \mathrm{C}$ for $30 \mathrm{~min}$ and left to stand for $10 \mathrm{~min}$. The supernatant was brought to $10^{3}$ final dilution before inoculation [45]. Then $150 \mu \mathrm{L}$ of diluted supernatant were added to the microplate and placed in an incubator at $25^{\circ} \mathrm{C}$ in the dark for 9 days. Absorbances at $590 \mathrm{~nm}$ and $750 \mathrm{~nm}$ were measured every $24 \mathrm{~h}$ with a microplate reader, and the distribution of 31 carbon sources in Biolog-Eco plates were identified (Additional file 1: Table S2).

The relative absorbance of each carbon source pore indicates the ability of the microbial community to utilize the carbon source. The average well color development $(A W C D)$ of the pores reflects the average metabolic capacity of the microbial community with 31 carbon sources, indicating the overall metabolic activity of the microorganisms. The calculation of $A W C D$ was as follows:

$$
A W C D=\sum\left(C_{i}-R_{0}\right) / 31
$$

where $C_{i}$ is the absorbance at $590 \mathrm{~nm}$ minus $750 \mathrm{~nm}$ of each carbon source hole, and $R_{0}$ is the absorbance of the control hole.

\subsection{Root exudation determination}

A liquid chromatograph mass spectrometer (Ultimate 3000LC, Q Exactive Thermo Fisher Scientific, San Jose, CA, USA) was used to measure the composition of root exudation. Five $\mathrm{mL}$ of exudate were freezedried, $300 \mu \mathrm{L}$ of methanol and $10 \mu \mathrm{L}$ of internal standard $(3 \mathrm{mg} / \mathrm{mL}$, dichlorophenylalanine) were added, homogenized for $1 \mathrm{~min}$, centrifuged at $12000 \mathrm{rpm}$ for $15 \mathrm{~min}$ at $4{ }^{\circ} \mathrm{C}$, and $200 \mu \mathrm{L}$ of supernatant were transferred into a vial. Compounds with positive and negative ion modes were determined with a Hyper Gold $\mathrm{C} 18$ column $(100 \mathrm{~mm} \times 2.1 \mathrm{~mm}, 1.9 \mu \mathrm{m})$. Column temperature was $45^{\circ} \mathrm{C}$, the flow rate was 0.35 $\mathrm{mL} / \mathrm{min}$ and mobile phase composition A was: water $+5 \%$ acetonitrile $+0.1 \%$ formic acid, and $B$ was: acetonitrile $+0.1 \%$ formic acid. The injection volume was $10 \mu \mathrm{L}$ and auto-sampler temperature was $4{ }^{\circ} \mathrm{C}$. The compound databases (Predicted Compositions, mzCloud Search, ChemSpider Search) were used for comparison.

\subsection{Statistical analyses}


One-way analysis of variance (ANOVA) for three or more treatments, or T-test for two treatments were used to test for differences among or between means (SPSS 25.0, SPSS Inc., Chicago, IL, USA). Statistical analysis and graphing were done with R 3.6.1 and Origin 2018, and principal component analysis (PCA), principal coordinates analysis (PCOA) and redundancy analysis (RDA) were done in R. Structural equation modelling (SEM) used AMOS Graphics based on the site score of the first axis of PCoA for bacterial communities, and PCA for root exudates and AWCD. Bacterial communities were based on weighted UniFrac distances, PCA of root exudates and AWCD based on Bray-Curtis distances. Data of soil physico-chemical properties were log transformed. The initial model was simplified by a stepwise removal of uninformative paths, until a suitable model was generated. In addition, modification indices were used to identify missing paths. The $\chi 2$ test and the root mean square error of approximation (RMSEA) tested the overall goodness of fit, which is indicated by a low $\chi 2$ and a high probability $(P>$ 0.05), and a RMSEA near 0.

\subsubsection{Network construction and visualization}

The scale function standardized the original data and then the network analysis of microbial communities and root exudates were completed with weighted gene co-expression network analysis (WGCNA) in R. To reduce the redundancy of data, some values with little information were removed, and the mad function in $\mathrm{R}$ was used to screen the OTU/exudation (75\% before the median absolute deviation and greater than 0.01). The network was constructed as an unsigned type, and the Pearson correlation coefficient was used to test for relationships. To make the constructed network conform more to the scale-free feature, the appropriate soft threshold was calculated to complete the integration of the modules. OTUs/exudations were classified into modules, which were represented by different colors.

Correlation analysis was employed between modules (module eigengenes, ME) and plant species after modules merged. The adjacency and colSums functions in the WGCNA package were used to calculate the connectivity of the nodes. The Pearson correlation coefficient was used to determine the relation between root exudates and microorganisms. The accepted significance was $P<0.05$, and holm was used for multiple test adjustment. The visualization of the network was completed by Cytoscape 3.7.0 [46], which only showed the nodes and edges with significant correlations. The colors of nodes were consistent with the colors of the module where they were located.

\subsubsection{S rRNA gene amplicon analysis}

Potential microbial biomarkers were obtained by the linear discriminate analysis (LDA) effect size (LEfSe) method (http://huttenhower.sph.harvard.edu/lefse/), using 16S rRNA gene sequences to calculate the metabolic cycles and pathways in the Kyoto Encyclopedia of Genes and Genomes (KEGG) with picrusts (http://huttenhower.sph.harvard.edu/galaxy/picrusts/) [47]. Bray-Curtis, considered the evolutionary distance between species, was used to analyze the main coordinates of the samples and to identify the differences.

\section{Results}




\subsection{Soil microbial community carbon metabolism}

The $A W C D$ of all samples increased with incubation time (Fig. 1A) and of the rhizosphere microorganisms of poisonous plant species was higher than the bulk (non-rhizosphere) soil in the four levels of degraded grassland. This indicated that rhizosphere microorganisms of poisonous plants had higher metabolic activity and could make better use of the carbon source in the Biolog-Eco plates. The AWCD reached maximum rate within 48-96 h, and the $72 \mathrm{~h}$ measurements were used for PCA (Fig. 1B). The values of the first principal component in the four degraded grasslands of $S, H, M$, and $L$ were $54.2 \%$, $50.5 \%, 48.5 \%$, and $47.0 \%$, respectively, and indicated that the microorganisms of different plant rhizospheres and bulk soil used carbon sources differently (Fig. 1B).

There were $12,13,11$, and 13 carbon sources that were significantly $(P<0.05)$ related to principal component 1 in S, H, L, and M, respectively (Additional file 1: Table S3). Except for D-xylose, which was correlated negatively with $L(P<0.05)$, all were correlated positively. The microorganisms in $S$ had greater metabolic activity for amino acids than other carbon sources. The rhizosphere microorganisms in each degraded grassland used six more types of carbon sources than bulk soils, and the utilization efficiency of amino acids by soil microbes was greater than for other carbon sources $(P<0.05)$ (Table 1$)$. In $\mathrm{L}$ grassland, bulk soil had a higher utilization efficiency for carbohydrates, while rhizosphere soil had a higher utilization efficiency for phenolic acids $(P<0.05)$ (Table 1$)$. 
Table 1

Soil utilization of different carbon sources by microorganisms in $72 \mathrm{~h}$ cultivation

\begin{tabular}{|c|c|c|c|c|c|c|c|}
\hline Samples & Amines & $\begin{array}{l}\text { Phenolic } \\
\text { acids }\end{array}$ & $\begin{array}{l}\text { Carboxylic } \\
\text { acids }\end{array}$ & Carbohydrates & $\begin{array}{l}\text { Amino } \\
\text { acids }\end{array}$ & Polymers & $\begin{array}{l}P \\
\text { value }\end{array}$ \\
\hline $\mathrm{S}-\mathrm{Nr}$ & $0.226 \mathrm{~B}$ & $0.135 \mathrm{Cb}$ & $0.116 \mathrm{Cc}$ & $0.249 \mathrm{Bc}$ & $\begin{array}{l}0.340 \\
A b\end{array}$ & 0.258 B & $\begin{array}{l}P< \\
0.001\end{array}$ \\
\hline S-Sg & $0.352 \mathrm{~B}$ & $0.518 \mathrm{ABa}$ & $0.401 \mathrm{Ba}$ & $0.517 \mathrm{ABab}$ & $\begin{array}{l}0.641 \\
\mathrm{Aa}\end{array}$ & $0.390 \mathrm{~B}$ & $\begin{array}{l}P= \\
0.040\end{array}$ \\
\hline $\mathrm{S}-\mathrm{Oo}$ & $0.364 \mathrm{~B}$ & $0.363 \mathrm{Bab}$ & $0.229 \mathrm{Bbc}$ & $0.656 \mathrm{Aa}$ & $\begin{array}{l}0.562 \\
\mathrm{Aa}\end{array}$ & $0.349 \mathrm{~B}$ & $\begin{array}{l}P< \\
0.001\end{array}$ \\
\hline S-Pk & $0.325 \mathrm{~B}$ & $0.498 \mathrm{ABa}$ & $0.330 \mathrm{Bab}$ & $0.543 \mathrm{ABab}$ & $\begin{array}{l}0.639 \\
\text { Aa }\end{array}$ & $0.459 \mathrm{AB}$ & $\begin{array}{l}P= \\
0.095\end{array}$ \\
\hline \multirow[t]{2}{*}{ S-Lv } & $\begin{array}{l}0.338 \\
\mathrm{BC}\end{array}$ & $0.248 \mathrm{Cb}$ & $0.271 \mathrm{Cab}$ & $0.409 \mathrm{Bbc}$ & $\begin{array}{l}0.592 \\
\mathrm{Aa}\end{array}$ & $0.273 \mathrm{C}$ & $\begin{array}{l}P< \\
0.001\end{array}$ \\
\hline & $\begin{array}{l}P= \\
0.232\end{array}$ & $P=0.015$ & $P=0.010$ & $P=0.003$ & $P<0.01$ & $P=0.153$ & \\
\hline $\mathrm{L}-\mathrm{Nr}$ & $\begin{array}{l}0.306 \\
\mathrm{BC}\end{array}$ & $0.274 \mathrm{C}$ & $0.251 \mathrm{C}$ & $0.632 \mathrm{~A}$ & $\begin{array}{l}0.487 \\
A B\end{array}$ & $0.314 \mathrm{BC}$ & $\begin{array}{l}P= \\
0.008\end{array}$ \\
\hline \multirow[t]{2}{*}{ L-Mk } & $\begin{array}{l}0.558 \\
B C\end{array}$ & $0.841 \mathrm{~A}$ & $0.430 \mathrm{C}$ & $0.587 \mathrm{BC}$ & $\begin{array}{l}0.769 \\
A B\end{array}$ & $0.500 \mathrm{C}$ & $\begin{array}{l}P= \\
0.009\end{array}$ \\
\hline & $\begin{array}{l}P= \\
0.049\end{array}$ & $P=0.006$ & $P=0.148$ & $P=0.762$ & $\begin{array}{l}P= \\
0.009\end{array}$ & $P=0.017$ & \\
\hline $\mathrm{M}-\mathrm{Nr}$ & 0.207 B & $0.126 \mathrm{~B}$ & $0.145 \mathrm{Bc}$ & $0.281 \mathrm{ABb}$ & $\begin{array}{l}0.399 \\
\text { Ac }\end{array}$ & $\begin{array}{l}0.269 \\
\text { ABd }\end{array}$ & $\begin{array}{l}P= \\
0.020\end{array}$ \\
\hline M-Al & $0.421 \mathrm{~B}$ & 0.487 B & $0.202 \mathrm{Cbc}$ & $0.402 \mathrm{Bab}$ & $\begin{array}{l}0.654 \\
\mathrm{Aa}\end{array}$ & $\begin{array}{l}0.358 \\
\text { Bcd }\end{array}$ & $\begin{array}{l}P= \\
0.001\end{array}$ \\
\hline M-Ef & 0.382 & 0.468 & $0.253 a b c$ & $0.443 a b$ & $\begin{array}{l}0.443 \\
\text { bc }\end{array}$ & $0.366 \mathrm{~cd}$ & $\begin{array}{l}P= \\
0.616\end{array}$ \\
\hline M-Mk & $0.379 \mathrm{~B}$ & $0.357 \mathrm{BC}$ & 0.272 Cabc & $0.523 \mathrm{Aab}$ & $\begin{array}{l}0.550 \\
A b\end{array}$ & $\begin{array}{l}0.493 \\
\text { Aab }\end{array}$ & $\begin{array}{l}P< \\
0.001\end{array}$ \\
\hline M-Ap & $\begin{array}{l}0.419 \\
\mathrm{BC}\end{array}$ & $0.514 \mathrm{ABC}$ & $0.338 \mathrm{Cab}$ & $0.658 \mathrm{ABa}$ & $\begin{array}{l}0.666 \\
\mathrm{Aa}\end{array}$ & $\begin{array}{l}0.592 \\
\mathrm{ABa}\end{array}$ & $\begin{array}{l}P= \\
0.041\end{array}$ \\
\hline M-Lv & 0.484 & 0.460 & $0.409 \mathrm{a}$ & $0.647 \mathrm{a}$ & $0.629 a$ & 0.412 bc & $\begin{array}{l}P= \\
0.119\end{array}$ \\
\hline
\end{tabular}

Note: Values with different lowercase letters in the same column indicate significant differences between them $(P<0.05)$. Values with different capital letters in the same row indicate significant differences between them $(P<0.05)$. L, lightly degraded grassland; M, moderately degraded grassland; $\mathrm{H}$, heavily degraded grassland; $\mathrm{S}$, degraded sown grassland. $\mathrm{Nr}$, non-rhizosphere soil. Al, Ajuga lupulina; Ef, Euphorbia fischeriana; Sg, Sphallerocarpus gracilis; Oo, Oxytropis ochrocephala; Mk, Morina kokonorica; Pk, Pedicularis kansuensis; An, Artemisia nanschanica; Ad, Artemisia dubia; Ap, Aconitum pendulum; Lv, Ligularia virgaurea. 


\begin{tabular}{|c|c|c|c|c|c|c|c|}
\hline Samples & Amines & $\begin{array}{l}\text { Phenolic } \\
\text { acids }\end{array}$ & $\begin{array}{l}\text { Carboxylic } \\
\text { acids }\end{array}$ & Carbohydrates & $\begin{array}{l}\text { Amino } \\
\text { acids }\end{array}$ & Polymers & $\begin{array}{l}P \\
\text { value }\end{array}$ \\
\hline & $\begin{array}{l}P= \\
0.202\end{array}$ & $P=0.062$ & $P=0.024$ & $P=0.040$ & $\begin{array}{l}P= \\
0.002\end{array}$ & $P=0.001$ & \\
\hline $\mathrm{H}-\mathrm{Nr}$ & $0.229 \mathrm{c}$ & $0.157 c$ & $0.177 \mathrm{c}$ & $0.311 \mathrm{c}$ & $0.344 \mathrm{~d}$ & $0.281 d$ & $\begin{array}{l}P= \\
0.088\end{array}$ \\
\hline H-Al & $\begin{array}{l}0.329 \\
\text { Babc }\end{array}$ & $0.229 \mathrm{Cbc}$ & $\begin{array}{l}0.275 \\
\text { BCabc }\end{array}$ & $0.304 \mathrm{BCC}$ & $\begin{array}{l}0.505 \\
\text { Abc }\end{array}$ & $\begin{array}{l}0.354 \\
\text { Bcd }\end{array}$ & $\begin{array}{l}P< \\
0.001\end{array}$ \\
\hline $\mathrm{H}-\mathrm{Ef}$ & $\begin{array}{l}0.315 \\
\text { Cabc }\end{array}$ & $0.256 \mathrm{Cbc}$ & 0.298 Cabc & $0.627 \mathrm{Aa}$ & $\begin{array}{l}0.508 \\
\mathrm{ABbc}\end{array}$ & $\begin{array}{l}0.383 \\
\text { BCbcd }\end{array}$ & $\begin{array}{l}P= \\
0.002\end{array}$ \\
\hline $\mathrm{H}-\mathrm{Sg}$ & $\begin{array}{l}0.287 \\
\mathrm{Cbc}\end{array}$ & $0.399 \mathrm{Bab}$ & $0.235 \mathrm{Cbc}$ & 0.529 Aabc & $\begin{array}{l}0.526 \\
\text { Abc }\end{array}$ & $\begin{array}{l}0.376 \\
\text { Bbcd }\end{array}$ & $\begin{array}{l}P< \\
0.001\end{array}$ \\
\hline $\mathrm{H}-\mathrm{Mk}$ & $\begin{array}{l}0.354 \\
a b c\end{array}$ & $0.442 a b$ & $0.338 a b c$ & $0.534 \mathrm{abc}$ & $\begin{array}{l}0.615 \\
a b\end{array}$ & $\begin{array}{l}0.440 \\
a b c\end{array}$ & $\begin{array}{l}P= \\
0.345\end{array}$ \\
\hline H-An & $\begin{array}{l}0.262 \\
\text { ABbc }\end{array}$ & $0.217 \mathrm{Bbc}$ & $0.179 \mathrm{Bbc}$ & $0.353 \mathrm{Abc}$ & $\begin{array}{l}0.384 \\
\text { Abc }\end{array}$ & $\begin{array}{l}0.287 \\
\text { ABd }\end{array}$ & $\begin{array}{l}P= \\
0.021\end{array}$ \\
\hline $\mathrm{H}-\mathrm{Ad}$ & $0.486 a$ & $0.416 a b$ & $0.272 a b c$ & $0.553 a b$ & $\begin{array}{l}0.523 \\
\mathrm{~cd}\end{array}$ & $\begin{array}{l}0.444 \\
a b c\end{array}$ & $\begin{array}{l}P= \\
0.057\end{array}$ \\
\hline $\mathrm{H}-\mathrm{Ap}$ & $\begin{array}{l}0.440 \\
a b\end{array}$ & $0.540 \mathrm{a}$ & $0.348 a b$ & $0.699 a$ & $0.740 \mathrm{a}$ & $0.536 \mathrm{a}$ & $\begin{array}{l}P= \\
0.074\end{array}$ \\
\hline $\mathrm{H}-\mathrm{Lv}$ & $\begin{array}{l}0.427 \\
\mathrm{Bab}\end{array}$ & $0.403 \mathrm{Bab}$ & $0.429 \mathrm{Ba}$ & $0.716 \mathrm{Aa}$ & $\begin{array}{l}0.662 \\
\text { Aab }\end{array}$ & $\begin{array}{l}0.491 \\
\mathrm{Bab}\end{array}$ & $\begin{array}{l}P= \\
0.001\end{array}$ \\
\hline$P$ value & $P=0.04$ & $P=0.024$ & $P=0.044$ & $P=0.003$ & $\begin{array}{l}P= \\
0.001\end{array}$ & $P=0.003$ & \\
\hline \multicolumn{8}{|c|}{$\begin{array}{l}\text { Note: Values with different lowercase letters in the same column indicate significant differences } \\
\text { between them }(P<0.05) \text {. Values with different capital letters in the same row indicate significant } \\
\text { differences between them }(P<0.05) \text {. L, lightly degraded grassland; M, moderately degraded } \\
\text { grassland; H, heavily degraded grassland; S, degraded sown grassland. Nr, non-rhizosphere soil. Al, } \\
\text { Ajuga lupulina; Ef, Euphorbia fischeriana; Sg, Sphallerocarpus gracilis; Oo, Oxytropis ochrocephala; } \\
\text { Mk, Morina kokonorica; Pk, Pedicularis kansuensis; An, Artemisia nanschanica; Ad, Artemisia dubia; } \\
\text { Ap, Aconitum pendulum; Lv, Ligularia virgaurea. }\end{array}$} \\
\hline
\end{tabular}

\subsection{Convergence and microbial composition in bulk soil and rhizosphere}

The Illumina MiSeq 16S sequence determined the bacterial diversity in the rhizosphere soil of poisonous plant species and bulk soil. A total of 12,282 operational taxonomic units (OTUs) were identified in 2017 (5923, 8031, 6877, and 3110 in S, H, L and M, respectively) and 5447 OTUs were identified in 2018 (2730, 2525, 1992 and 2898 in S, L, M and H, respectively). OTUs were classified into 44 microbial phyla in 2017 and 41 microbial phyla in 2018 with Proteobacteria, Actinobacteria, Acidobacteria and Planctomycetes the four most abundant in all soil groups (Fig. 2). The bulk soil of $L$ grassland had the lowest a-diversity 
indices of bacterial and fungal communities across all samples (Kruskal-Wallis with Kruskal.test, $P<$ 0.05) (Fig. 3a).

If roots establish stable associations with microbial communities across different habitats, a strong hostfiltering effect on habitats is expected. Analysis of microbial community structure based on average BrayCurtis distances across the 4 degraded grasslands revealed that bacterial and fungal communities in bulk soil and in rhizosphere clustered by grassland type (Figs. 3a and 3c). This pattern was corroborated by permutational multivariate analysis (PERMANOVA) of variance with Bray-Curtis distances (Adonis function in $\mathrm{R}$ library vegan), which indicated that species $\times$ habitat explained more of the variation in microbial community (Adonis: degrees of freedom (d.f.) $=21$; bacterial: coefficient of determination $\left(R^{2}\right)=$ $0.53 ; P<0.001$; fungal: $\mathrm{R}^{2}=0.32 ; P=0.59$ ) than compartment (d.f. $=1$; bacterial: $\mathrm{R}^{2}=0.04 ; P<0.001$; fungal: $\mathrm{R}^{2}=0.01 ; P=0.62$ ), habitat (d.f. $=3$; bacterial: $\mathrm{R}^{2}=0.16 ; P<0.001$; fungal: $\mathrm{R}^{2}=0.05 ; P=0.91$ ) or species (d.f. $=10$; bacterial: $\mathrm{R}^{2}=0.27 ; P<0.001$; fungal: $\left.\mathrm{R}^{2}=0.15 ; P=0.29\right)$ (Fig. 3b). The bacterial community was affected to a greater extent than the fungal community by habitat and species.

PCoA ordinates based on Bray-Curtis distances revealed marked differences in soil bacterial and fungal communities in the 4 habitats. The bacterial community in $\mathrm{M}$ and the fungal community in $\mathrm{S}$, in particular, were separated clearly from the others. These differences appeared in the same plant species in different habitats, suggesting divergence in the microbial community composition in plant rhizosphere (Fig. 3c).

Nitrate nitrogen $\left(\mathrm{NO}_{3}-\mathrm{N}\right)$ in $\mathrm{L}$ grassland was lower than the other three habitats $(P<0.05)$, while ammonium nitrogen $\left(\mathrm{NH}_{4}-\mathrm{N}\right)$ exhibited an opposite trend (Fig. 4a). The concentrations of TN, AP and TOC in bulk soil of the four habitats were lower than in the rhizosphere soil (Additional file 1: Table S4). Redundancy analysis showed that soil physico-chemical properties explained $28.3 \%$ of the variation in rhizosphere bacterial communities (Fig. 4b) $(P<0.05)$, but had no effect on fungal communities. The bacterial communities were correlated positively with TP, $\mathrm{pH}$ and $\mathrm{AP}$, but negatively with $\mathrm{TN}, \mathrm{TOC}, \mathrm{NO}_{3}$, $\mathrm{NH}_{4}$ and WC (Fig. 4b).

\subsection{The potential biomarkers among different sampling sites}

LEfSe analyses identified the statistical significance of abundant taxa of different poisonous plant species in the same degraded grassland and the same poisonous plant species in different grasslands (Figs. 5 and S2). The LDA values are presented in Figs. 5b and 5d. Plant species and the level of grassland degradation were the main factors in structuring the soil microbiota. Various taxa were enriched in different soil cores and specific enrichments were evident in rhizospheres of poisonous plant species in the same habitat (Additional file 1: Figure S2) and of L. virgaurea in the four habitats (Fig. $5 \mathrm{c}$ ). The rhizosphere of poisonous plant species enriched more microbial taxa than bulk soil or rhizosphere of high-quality grasses (E. nutans and Kobresia pygmaea) (Additional file 1: Figure S2). Bulk soil enriched more taxa than rhizosphere in M, especially Acidobacteria, Chloroflexi and Gemmatimonadetes (Fig. 5a). 


\subsection{Functional prediction analysis in rhizosphere microbial communities}

Cell growth and death pathways of KEGG level 2 in $L$. virgaurea were greater than in other poisonous plant species $(P<0.05)$ (Fig. 6) and in $\mathrm{H}$ and $\mathrm{M}$ were greater than in $\mathrm{S}$ and $\mathrm{L}(P<0.05)$ (Fig. 6). For the three poisonous plant species in $S$, except for the cell growth and death pathways, other pathways in $L$. virgaurea were significantly lower than in E. nutans and $P$. kansuensis (Fig. 6a). Pathway metabolism of terpenoids and polyketides in Morina kokonorica was lower than in K. pygmaea and E. nutans in $\mathrm{L}(P<$ 0.05). Metabolism of co-factors and vitamins in L. virgaurea was lower than in M. kokonorica and $K$. pygmaea $(P<0.05)$ in L (Fig. 6b), but of amino acids and carbohydrates were higher than in Aconitum pendulum $(P<0.05)$ (Fig. 6c). The cell motility and signal transduction in $L$. virgaurea in $\mathrm{S}$ was higher than in $\mathrm{H}, \mathrm{L}$ and $\mathrm{M}(P<0.05)$ (Fig. 6d).

\subsection{Relationship of modules of root exudates and rhizosphere bacterial community}

In total, 3613 effective OTUs and 1092 root exudates were obtained for network construction after screening. After the mad function removed unimportant values, the sample clustering results were consistent. There was similarity in results between OTU and root exudates, in which L. virgaurea was significantly different $(P<0.05)$ from the other poisonous plant species (Figs. 7 and S4). The rhizosphere microorganisms and root exudates of $E$. nutans and $P$. kansuensis were similar. Fifteen modules were combined in the clusterings in 16S OTUs (Additional file 1: Table S5; Additional file 1: Figure S4). A high average connection degree emerged inside the turquoise module (39.25), which contained 1769 OTUs (Additional file 1: Table S5). This module was correlated with all soil groups and had a significant negative correlation with $L$. virgaurea. The strong correlation between the module eigengenes from the WGCNA network analysis and each plant species indicated that the plant rhizosphere accumulated microorganisms/root exudation in the module. After removing the turquoise module, the OTU correlation network filtering with threshold (0.2) showed that the connectivity within the module was higher, especially in the blue, midnight blue and red modules (Fig. 7A and C). The tan, salmon and cyan modules had few OTUs (Fig. 7C). P. kansuensis correlated with the red and tan modules $(P<0.05)$, S-Lv-MD with midnight blue, S-Lv-HD with green, H-Lv with black, blue and yellow, L-Lv with magenta, green yellow and pink, and M-Lv with cyan, brown, and purple (Figs. 7A, 7C, and S4).

Most root exudates contained benzene ring structures, including mainly esters, ketones, aromatic acids, alkenes, amino acids, phenols and derivatives. Poisonous plant species correlated with corresponding modules; $P$. kansuensis with pink $(P<0.05)$, M. kokonorica with green $(P<0.05)$, and $A$. pendulum with blue $(P<0.05)$. M-Lv correlated with black, magenta, and yellow modules $(P<0.05)$, L-Lv with red $(P<$ $0.05)$, S-Lv-HD with brown $(P<0.05)$, and S-Lv-MD and S-Lv-LD with turquoise $(P<0.05)$ (Additional file 1: Figure S5). There was no module related to $E$. nutans and $K$. pygmaea, indicating that the content of compounds in the root system of poisonous plant species were higher than non-poisonous grasses. It 
was evident that root exudates were plant species specific and each species had a unique module (Figs. 7B and 7D).

The correlation analysis heat map of the root exudate module and the bacterial module are presented in Additional file 1: Figure S6. In the OTU module corresponding to poisonous plant species, more than $85 \%$ had positive correlations with roots exudates. The pink (exudate) and red (OTU) modules correlated with $P$. kansuensis and L. virgaurea; magenta (exudate) with brown and purple (OTU) in M-Lv $(P<0.05)$; yellow (exudate) with cyan (OTU) in M-Lv $(P<0.05)$; red (exudate) with green yellow (OTU) in L-Lv $(P<0.05)$; and turquoise (exudate) with brown and green (OTU) in S-Lv $(P<0.05)$ (Figs. 8A and S6). It demonstrated that microorganisms had preferences for plant species exudates and, consequently, plant species could manipulate microorganisms through exudates from roots.

Figure 8A outlines the network between OTU and exudate modules. There were two networks in M-Lv. One network was cyan (OTU) and yellow (exudate), with 7 phyla $(n=28)$ in the cyan module (OTU) (Fig. 8Aa), and Actinobacteria (25\%) and Proteobacteria (43\%) being the main phyla. Twelve genera in the module were related to exudates $(P<0.05)$ (Additional file 1: Table S6), including Acidibacter, Pseudonocardia, Bauldia, Stenotrophomonas and Nocardioides. Approximately $60 \%$ of the compounds in the yellow module were alkaloids, lupinic acid, sesquiterpene, artemisinin and other secondary metabolites (Additional file 1: Table S6), and 70\% of the metabolites in the magenta module were alkaloids, coumarins and derivatives, especially alkaloids. The second network was OTU modules (brown and purple) and magenta (exudate) (Fig. 8Aa). The brown module had 14 main phyla $(\mathrm{n}=52)(P<0.05)$, of which Proteobacteria, Planctomycetes, Bacteroidetes and Chloroflexi were $26 \%, 16 \%, 12 \%$ and $10 \%$, respectively. It contained a large number of bacteria with nitrification and denitrification abilities, such as Flavobacterium, Luteimonas, Arenimonas and Planctomyces. There were 6 phyla $(n=21)$ in the purple module, mainly Chloroflexi (19\%), Plantomytomytes (24\%), and Proteobacteria (24\%) (Figs. 8Aa and 8C; Additional file 1: Table S6).

There were 17 OTUs and 34 exudates which were correlated with P. kansuensis (Fig. 8Ab; Additional file 1: Table S6). The 17 OTUs in the red module were divided into 5 phyla, including mainly Proteobacteria (41\%) and Bacteroidetes (41\%), while Alphaproteobacteria and Sphingobacteriia were abundant classes. There were 12 genera, including Aureimonas, Segetibacter, Methylobacterium, and Pleomorphomonas that related significantly to rhizosphere exudates $(P<0.05)$. Most of the root exudates were insecticides with insecticidal effects and some soil microorganism inhibitors (about 60\%), such as carbofuran, cycloheximide and flusilazole.

For L-Lv, 11 phyla $(n=44)$ were included in the green yellow module, and Planctomycetes and Firmicutes accounted for $29 \%$ and $27 \%$, respectively (Figs. 8Ac and 8C; Additional file 1: Table S6). Nineteen genera were sequenced out that promoted plant growth (Clostridium, Lactobacillus, Acidibacter) and also some pathogenic bacteria (Methylocella, Aquicella, Veillonella, Enterococcus) were included. About $80 \%$ of the exudation in the red module that related significantly to OTUs were intermediate metabolites, such as terpenes, alkaloids, sugars, and fatty acid conjugates. 
The blue (OTU) module was related significantly to the grey module (exudates) (Fig. 8Ad; Additional file 1: Table S6). For H-Lv, $99 \%$ of the compounds in the grey module was nitrogen-containing heterocyclic compounds, mainly amino acids. The blue module contained 94 OTUs, mainly Proteobacteria (38\%), Plantomytomytes (19\%) and Acidobacteria (10\%). The module contained bacteria with nitrogen fixation, nitrification and denitrification abilities, such as Mesorhizobium, Steroidobacter, Pirellula and Rhizobacter (Figs. 8Ad and 8C; Additional file 1: Table S6).

For S-Lv, 8 and 9 phyla in the green module (OTU) correlated with the turquoise (exudate) and brown (exudate) modules, respectively, among which Proteobacteria was the main phylum and Alphaproteobacteria the main class. It contained Mycobacterium, Inquilinus, Nitrospira, Pirellula, and Singulisphaera (Figs. 8Ae and 8C; Additional file 1: Table S6). Of the compounds in the turquoise module, $80 \%$ included alkaloid, sesquiterpene, coumarin and phenolic compounds, and some compounds that inhibit the growth of mold.

Overall, S-Pk, S-Lv, L-Lv, M-Lv, H-Lv had 5, 10, 11, 14 and 10 phyla, respectively, in the bacterial communities correlated with root exudates. The relative abundance of Actinobacteria $(0.50 \%, 0.71 \%$ and $0.69 \%)$, Bacteroidetes $(0.17 \%, 0.47 \%$ and $0.22 \%)$ and Proteobacteria $(0.99 \%, 3.52 \%$ and $2.53 \%)$ were contained in L-Lv, M-Lv and H-Lv, respectively, and the relative abundance was highest in M-Lv. Some unique dominant phyla were identified in different habitats. For relative abundance of phyla $>0.1 \%$, there were Cyanobacteria (1.15\%) and Firmicutes (2.82\%) in L-Lv, Chloroflexi $(0.11 \%)$ in M-Lv; Gemmatimonadetes (0.26\%) in H-Lv; Bacteroidetes (0.16\%) in S-Pk; Acidobacteria (0.6\%), Chloroflexi $(0.12 \%)$ and Proreobacteria $(0.69 \%)$ in S-Lv, and Acidobacteria $(0.88 \%$ and $0.55 \%)$ and Planctomycetes $(0.23 \%$ and $0.37 \%$ ) in M-Lv and H-Lv (Fig. 8B).

\subsection{Potential drivers of the variation in degraded grassland}

The potential drivers of the composition of bacterial communities were assessed by a SEM approach. $\mathrm{NH}_{4}-\mathrm{N}$ constituted the strongest direct driver of 22 bacterial communities in the 4 habitats (Fig. 9a) and pH (Fig. 9b), TOC, $\mathrm{NH}_{4}-\mathrm{N}$ and $\mathrm{TN}$ also had significant effects. Soil physico-chemical properties influenced the composition of bacterial communities and Shannon diversity, and some soil properties influenced $\mathrm{NH}_{4}-\mathrm{N}$. Additional but weak links were detected between the composition of root exudates and $\mathrm{pH}$, but root exudates and $A W C D$ did not affect rhizosphere bacterial communities (Fig. 9).

\section{Discussion}

\subsection{Soil physical and chemical properties and soil microbial carbon metabolism in degraded grasslands}

The concentrations of TOC, TN, $\mathrm{NH}_{4}-\mathrm{N}$ and AP in bulk soil of $\mathrm{L}$ were higher than in bulk soil of more degraded grasslands (Fig. 4a; Additional file 1: Table S4) and, therefore, the degradation of grassland led to the loss of soil nutrients, which was consistent with other studies $[33,48]$. The concentrations of 
nutrients in rhizosphere soil were higher than in bulk soil, which indicated that the rhizosphere contained exudated organic matter from the plants, since no fertilizer was applied to the grassland.

Soil microorganisms could use different types of organic matter when cultivated in Biolog-Eco plates. The $A W C D$ of rhizosphere microorganisms and, consequently, the microbial carbon metabolism activity of rhizosphere soil was greater than in bulk soil. Similar results were reported by Fang et al. [49] when examining five grasses (Sudan grass, ryegrass, tall fescue, crested wheatgrass, and switch grass). The release of root exudates and root litter provided a substrate for microorganisms, which led to the higher carbon metabolism of microorganisms in the rhizosphere than in bulk soil. The accumulation of rhizosphere microorganisms was associated with the different types and amounts of exudates [50,51]. In support, Zhalnina et al. [51]showed that the assembly of rhizosphere microorganisms in Avena was mediated by the combined effects of root exudates and the preference of microbial substrates.

\subsection{Lefse and modular analyses of rhizosphere microorganisms}

The phylogenetic structure of bacteria displayed aggregation in bulk and rhizosphere soils of poisonous plant species. This suggested that each vegetation type was associated with a unique and defined bacterial community by niche filtering, which was consistent with previous studies [52]. In addition, bacteria and fungi in the same habitat were clustered, suggesting convergence. These successful colonists in the same niche could either compete for available resources or form a stable co-existing community through mutual cooperation $[53,54,55]$. The Lefse analysis displayed a greater abundance of biomarker bacteria in the rhizosphere soil than in the bulk soil. During degradation, the turf layer is displaced or removed, which leads to soil nutrients being lost and oligotrophic microorganisms (e.g., Acidobacteria, Chloroflexi and Gemmatimonadetes) being accumulated. However, with the invasion of poisonous plants, the roots exudate compounds [56], resulting in an increase in the proportion of eutrophic microorganisms and decrease in the proportion of oligotrophic microorganisms [57].

The rhizosphere of poisonous plant species formed a larger and more complex network than in nonpoisonous plant species (e.g., E. nutans and K. pygmaea). Modules were identified in the network that were likely caused by microbial-microbial interactions or cooperative mutations in response to the rhizosphere. It was reported that plant rhizosphere microbial communities differed [58,59] due to plant species, varieties or genotypes [60]. In the present study, the modules were related to some plant species, especially in $L$. virgaurea and $P$. kansuensis, and the connectivity within the module was greater than the connectivity between modules. The bacterial community compositions of $P$. kansuensis and $E$. nutans were similar; $P$. kansuensis is a herb that parasitizes Gramineae [61], which could explain the similarity of their bacterial community structure.

\subsection{Effect of density on root exudates and rhizosphere microorganisms}


Three densities of $L$. virgaurea were identified in the present study. There was a decrease in density of $L$. virgaurea in high density areas due to deaths, which may have been caused by autotoxicity and/or 'selfthinning'. Autotoxicity is an allelopathy in which an individual inhibits the growth of other individuals of the same species by releasing autotoxins [62]. Some autotoxins, including phenolics, omilactone B, artemisinin, phenolic acids, and cyclic hydroxamic acids [63], inhibit or delay the germination and growth of conspecific plants [64]. In degraded sown grassland in the present study, high-density L. virgaurea had a significantly related exudation module, while the middle and low densities had significantly related bacterial modules.

\subsection{Root exudates act as potential stimulants for rhizosphere bacteria}

Root exudates affect the composition of rhizosphere microorganisms, which has been labelled as the 'rhizosphere effect' $[65,66]$, and has been observed in a large number of plant species and soil types [67, 68]. However, this is not always the case. In this study, root exudates of $P$. kansuensis and $L$. virgaurea were correlated with rhizosphere microorganisms, confirming the rhizosphere effect, while roots of $M$. kokonorica and $A$. pendulum released unique compounds, but were not correlated with rhizosphere microorganisms. It was reported that Arabidopsis enriched various microbial taxa in bulk soil to colonize the rhizosphere by secreting different root exudates [59]. The root exudates released by different plant species were complex, and the adjacent growth of different plants can result in different rhizosphere microbial communities [69].

Plants secreted bio-active compounds to regulate rhizosphere microbiota, thereby affecting the growth and defense of the next-generation of plants $[16,70]$. The production and excretion of coumarin was found to be beneficial to the interaction among probiotics in plant roots and root microbiota $[56,71,72]$. L. virgaurea, a perennial herb with a wide niche, had a cell growth and death of KEGG levels higher than in other plants, which may be due to differences in rhizosphere microorganisms/root exudation.

When the roots of Lupinus albus mature, organic acids are released that decrease the $\mathrm{pH}$ of soil to inhibit bacteria [73]. The SEM demonstrated that $\mathrm{pH}$ influenced the bacterial communities directly [74], while root exudates and bacterial communities had weak effects. The specific traits of plants in the complex degraded grasslands had no discernible effect on the composition of their rhizosphere, which was also reported in temperate grasslands [4]. In the present study, approximately $60 \%$ of the pink modules (exudates) in P. kansuensis were insecticides, disinfectants, and attractants for insects. Huang et al. [29] reported that Arabidopsis produced specialized triterpenes that maintained specific microbiota, and could shape and customize the microorganisms within and around its roots. The content of modules for $L$. virgaurea contained mainly alkaloids, amino acids, phenols, aromatic organic acids and coumarin. Compared with amino acids and sugars, the phenols exudated by the root system had more significant correlations with Acidobacteria, Actinomycetes, Bacteroides and Cyanobacteria [75]. Flavonoids, phenolic compounds, have been studied extensively for their signaling role in plant rhizosphere [76]. 
The bacteria that were related to root exudates in this study were associated mainly with the nitrogen cycle; Rhizobiales (Alphaproteobacteria) in nitrogen fixation, Pseudomonas (Gammaproteobacteria) and Nitrospirae [77] in nitrification, and Rhodospirillaceae (Alphaproteobacteria) in denitrification [78]. In addition, there were Cytophagaceae (Cytophagia) and Planctomycetales, bacteria involved in ammonia oxidation, Pirellulla, Planctomyces, and Methylobacterium in methane oxidation in the carbon cycle, Mycobacterium in decomposing organic carbon [79], and Acidibacter, in degrading protein and ingesting acidic substances.

The samples were taken in August, which was the peak time for the development of poisonous plant species. Previous studies reported that plant rhizosphere microorganisms and root exudates undergo changes during plant development [51]. M. kokonorica with green module (exudates) and A. pendulum with blue module (exudates) had high correlations; however, there was no correlation with rhizosphere microorganism, indicating that the compounds in the exudate did not affect the assembly of rhizosphere microorganisms. This may be unique to the species themselves, or it may have been caused by the sampling time.

\subsection{Network analysis}

Many studies on microbes have focused on identifying modules in networks due to their importance in ecology $[50,80,81]$. In the rhizosphere network, microbial/exudate modules related to plant species were identified, and different plant species corresponded to different modules. These modules play a crucial role in the abundance of plant species. The disappearance of putative taxa may lead to the disintegration of modules and networks [82, 83], pointing out the importance of microorganisms/exudation in maintaining ecosystem stability $[50,84]$.

\section{Conclusions}

Soil nutrients, including TOC, TN and AP, and microorganisms in the rhizosphere of poisonous plant species were higher than in non-poisonous plant species, which indicated that the roots of poisonous plants were better at accumulating nutrients and microorganisms in poor soils. In the process of degradation, soil nutrients were lost, and the abundance of oligotrophic microorganisms increased in the bulk soil of bare land. Habitat and plant species affected the composition of the microbial community, for bacteria more so than fungi. Bacterial and fungal microorganisms in the same habitat showed convergence. Carbon metabolism activity and modular connectivity of rhizosphere microorganisms of poisonous plants were greater than in bulk soil $(P<0.05)$. Poisonous plant species exudated more compounds in the rhizosphere, that were more complex and of higher connectivity than non-poisonous plant species (K. pygmaea and E. nutans) $(P<0.05)$. The root exudates of $P$. kansuensis and $L$. virgaurea shaped the rhizosphere microbiota; $P$. kansuensis released mainly insecticides and disinfectants while $L$. virgaureais exudated mainly secondary metabolites, including terpenes, alkaloids, sugars, coumarins and lupinic acid, that contributed to self-growth. There were significant positive correlations between root exudates of plant species and rhizosphere microorganisms. Poisonous plant species adapted to different habitats and promoted self-growth and offspring viability through root exudates that benefitted the 
rhizosphere microorganisms. Understanding the adaptations of poisonous plant species could help explain their niche space and distribution and could provide options for direct manipulation of soil microbial communities through specific components of exudates.

\section{Abbreviations}

OTU: operational taxonomic unit

PCA: Principal component analysis

PCoA: Principal co-ordinates analysis

RDA: Redundancy analysis

WGCNA: weighted gene co-expression network analysis

L, lightly degraded native grassland

$M$, moderately degraded native grassland

$H$, heavily degraded native grassland

S, degraded sown grassland

$\mathrm{TN}$, total nitrogen

TP, total phosphorus

TOC, total organic carbon

AP, available phosphorus

$\mathrm{NO}_{3}$, nitrate nitrogen

$\mathrm{NH}_{4}$, ammonium nitrogen

WC, water content.

$\mathrm{Nr}$, non-rhizosphere soil
Al, Ajuga lupulina
Ef, Euphorbia fischeriana

Sg, Sphallerocarpus gracilis

Oo, Oxytropis ochrocephala 
Mk, Morina kokonorica

Pk, Pedicularis kansuensis

An, Artemisia nanschanica

Ad, Artemisia dubia

Ap, Aconitum pendulum

Lv, Ligularia virgaurea

En, Elymus nutans

Kp, Kobresia pygmaea.

LD, low density of L. virgaurea

$\mathrm{MD}$, middle density of $L$. virgaurea

$H D$, high densities of L. virgaurea.

\section{Declarations}

Ethics approval and consent to participate

Not applicable

Consent for publication

Not applicable.

Availability of data and materials

Sequence data are deposited in the NCBI Sequence Read Archive under the accession number PRJNA693171.

Competing interests

The authors declare that they have no competing interests.

\section{Funding}

This study was supported by the Second Tibetan Plateau Expedition (2019QZKK0302), the Natural Science Foundation of China $(31870433,41671508,31700396,31961143012)$ and National Key Research and Development Project (2016YFC0501906). 
Wenyin Wang: Data curation, Formal analysis, Methodology, Writing- original draft. Tianhua Jia: Field sampling, Methodology, Laboratory assays, Data curation. Tianyun Qi: Data curation. Shanshan Li: Data curation. A. Allan Degen: Writing - review and editing. Jin Han: Field sampling and Laboratory assays. Yanfu Bai: Field sampling. Tao Zhang: Field sampling. Shuai Qi: Field sampling. Mei Huang: Field sampling, Data curation. Zihao Li: Field sampling. Zhanhuan Shang: Funding acquisition, Conceptualization, Field sampling, Methodology, Formal analysis, Writing - review and editing. All authors read and approved the final manuscript.

\section{Author details}

${ }^{1}$ State Key Laboratory of Grassland Agro-Ecosystems, School of Life Sciences, Lanzhou University, Lanzhou, 730000, China. ${ }^{2}$ State Key Laboratory of Grassland Agro-Ecosystems, College of Pastoral Agriculture Science and Technology, Lanzhou University, Lanzhou 730020, China. ${ }^{3}$ Desert Animal Adaptations and Husbandry, Wyler Department of Dryland Agriculture, Blaustein Institutes for Desert Research, Ben-Gurion University of the Negev, Beer Sheva 8410500, Israel. ${ }^{4}$ Qinghai Provincial Key Laboratory of Restoration Ecology of Cold Areas, Northwest Institute of Plateau Biology, Chinese Academy of Science; Xining, 810008, China. ${ }^{5}$ Qinghai Provincial Key Laboratory of Adaptive Management on Alpine Grassland, Qinghai Academy of Animal and Veterinary Science, Qinghai University, Xining 810016, China.

\section{References}

1. Bais HP, Weir TL, Perry LG, Gilroy S, Vivanco JM. The role of root exudates in rhizosphere interactions with plants and other organisms. Annu. Rev. Plant Biol. 2006;57:233-266.

2. Callaway RM. Novel weapons: invasive plant suppresses fungal mutualists in America but not in its native Europe. Ecology. 2008;89:1043-1055.

3. de Vries FT, Williams A, Stringer F, Willcocks R, McEwing R, Langridge $\mathrm{H}$, et al. Changes in rootexudate-induced respiration reveal a novel mechanism through which drought affects ecosystem carbon cycling. New Phytol. 2019;224:132-145.

4. Vieira S, Sikorski J, Dietz S, Herz K, Schrumpf H, Bruelheide H, et al. Drivers of the composition of active rhizosphere bacterial communities in temperate grasslands. ISME J. 2020;14:463-475.

5. Zhang ZJ, Liu YJ, Yuan L, Weber E, van Kleunen M. Effect of allelopathy on plant performance: a meta-analysis. Ecol Lett. 2020. doi: 10.1111/ele.13627.

6. Philippot L, Raaijmakers JM, Lemanceau P, van der Putten WH. Going back to the roots: the microbial ecology of the rhizosphere. Nat Rev Microbiol. 2013;11(11):789-799.

7. Baetz U, Martinoia E. Root exudates: the hidden part of plant defense. Trends Plant Sci. 2014;19(2):90-98. 
8. Yelenik SG, D’Antonio CM. Self-reinforcing impacts of plant invasions change over time. Nature. 2013;503:517-520.

9. Wu JS, Yang PW, Zhang XZ, Shen ZX, Yu CQ. Spatial and climatic patterns of the relative abundance of poisonous vs. non-poisonous plants across the Northern Tibetan plateau. Environ Monit Assess. 2015;187:419.

10. Rodríguez-Caballero G, Caravaca F, Alguacil MM, Fernández-López M, Fennández-Gonzálerz AJ, Roldán A. Striking alterations in the soil bacterial community structure and functioning of the biological $\mathrm{N}$ cycle induced by Pennisetum setaceum invasion in a semiarid environment. Soil Biol Biochem. 2017;109:176-187.

11. Möhler H, Diekötter T, Herrmann JD, Donath TW. Allelopathic vs. autotoxic potential of a grassland weed-evidence from a seed germination experiment. Plant Ecol Divers. 2018;11(4):539-549.

12. Nunes KA, Fitzpatrick CR, Kotanen PM. Soil biota composition and the performance of a noxious weed across its invaded range. Ecography. 2019;42: 1671-1681.

13. Ehlers BK, Berg MP, Staudt M, Holmatrup M, Glasius M., Ellers J, et al. Plant Secondary Compounds in Soil and Their Role in Belowground Species Interactions. Trends Ecol Evol. 2020;35(8):716-730.

14. Badri DV, Vivanco JM. Regulation and function of root exudates. Plant Cell Environ. 2009;32(6):666681.

15. Cesco S, Neumann G, Tomasi N, Pinton R, Weisskopf L. Release of plant-borne flavonoids into the rhizosphere and their role in plant nutrition. Plant Soil. 2010;329(1-2):1-25.

16. Hu LF, Robert CAM, Cadot S, Zhang X, Ye M, Li BB, et al. Root exudate metabolites drive plant-soil feedbacks on growth and defense by shaping the rhizosphere microbiota. Nat. Commun. 2018;9(1):2738.

17. Huang ACC, Jiang T, Liu YX, Bai YC, Reed J, Qu BY, et al. A specialized metabolic network selectively modulates Arabidopsis root microbiota. Science. 2019;364(6440):eau6389.

18. Vives-Peris V, Ollas CD, Gómez-Cadenas A, Pérez-Clemente RM. Root exudates: from plant to rhizosphere and beyond. Plant Cell Reports. 2020;3:3-17.

19. Lorenzo P, Pereira CS, Rodríguez-Echeverría S. Different impact on soil microbes of allelopathic compounds released by the invasive Acacia dealbata Soil Biol Biochem. 2013;57:156-163.

20. Steinauer K, Chatzinotas A, Eisenhauer N. Root exudate cocktails: the link between plant diversity and soil microorganisms? Ecol Evol. 2016;6:7387-7396.

21. Winter S, Jung LS, Eckstein RL, Otte A, Donath TW, Kriechbaum M. Control of the toxic plant Colchicum autumnale in semi-natural grasslands: effects of cutting treatments on demography and diversity. J Appl Ecol. 2014;51:524-533.

22. Trognitz F, Hackl E, Widhalm S, Sessitsch A. The role of plant-microbiome interactions in weed establishment and control. FEMS Microbiol Ecol. 2016;92:fiw138.

23. Giggons SM, Lekberg Y, Mummey DL, Sangwan N, Ramsey PW, Gilbert JA. Invasive plants rapidly reshape soil properties in a grassland ecosystem. mSystems. 2017;2(2):e00178-16. 
24. Jin H, Yang XY, Liu RT, Yan ZQ, Li XD, Li XZ, et al. Bacterial community structure associated with the rhizosphere soils and roots of Stellera chamaejasme along a Tibetan elevation gradient. Ann Microbiol. 2018;68:273-286.

25. Mitchell AS. Poisonous plants in Northern Territory rangelands. The Australian Rangeland Journal. 1979;1(3):239-243.

26. Lu H, Wang SS, Zhou QW, Zhao YN, Zhao BY. Damage and control of major poisonous plants in the western grasslands of China-a review. The Rangeland Journal. 2012;34:329-339.

27. Li YY, Dong SK, Liu S, Wang X, Wen L, Wu Y. The interaction between poisonous plants and soil quality in response to grassland degradation in the alpine region of the Qinghai-Tibetan plateau. Plant Ecol. 2014;215:809-819.

28. Zhang R, Degen AA, Bai YF, Zhang T, Wang XM, Zhao XY, et al. The forb, Ajania tenuifolia, uses soil nitrogen efficiently, allowing it to be dominant over sedges and Graminase in extremely degraded grasslands: implications for grassland restoration and development on the Tibetan plateau. Land Degrad Dev. 2020;31:1265-1276.

29. Huang M, Shang ZH. Research progress on poisonous weed treatment technology in Qinghai-Tibet plateau. Acta Agrestia Sinica. 2019;27(5):1107-1116.

30. Tang L, Dong SK, Sherman R, Liu SL, Liu QR, Wang XX, et al. Changes in vegetation composition and plant diversity with rangeland degradation in the alpine region of Qinghai-Tibet Plateau. The Rangeland Journal. 2014;37(1):107-115.

31. Bao G, Suetsugu K, Wang H, Yao X, Liu L, Ou J, et al. Effects of the hemiparasitic plant Pedicularis kansuensis on plant community structure in a degraded grassland. Ecol Res. 2015;30:507-515.

32. Shang ZH, Yang SH, Wang YL, Shi JJ, Ding LM, Long RJ. Soil seed bank and its relation with aboveground vegetation along the degraded gradients of alpine meadow. Ecol Eng. 2016;90:268-277.

33. Dong SK, Shang ZH, Gao JX, Boone RB. Enhancing sustainability of grassland ecosystems through ecological restoration and grazing management in an era of climate change on Qinghai-Tibetan Plateau. Agric Ecosyst Environ. 2020;287:106684.

34. Cheng W, Sun G, Du LF, Wu Y, Zheng QY, Zhang HX, et al. Unpalatable weed Stellera chamaejasme L. provides biotic refuge for neighboring species and conserves plant diversity in overgrazing alpine meadows on the Tibetan Plateau in China. J Mt Sci. 2014;11(3):746-754.

35. Sun G, Luo P, Wu N, Qiu PF, Gao YH, Chen H, et al. Stellera chamaejasme increases soil N availability, turnover rates and microbial biomass in an alpine meadow ecosystem on the eastern Tibetan Plateau of China. Soil Biol Biochem. 2009;41(1):86-91.

36. Li L, Zhang T, Zhao C, Li Y, L Y, Mu C. Leaf and stem traits variation of Stellera chamaejasme Linn, with slope aspect in alpine steppe. Ecol Res. 2019;34:119-126.

37. Shang ZH, Hou YC, Pan DF, Yang SH, Shi JJ, Ding, LM, et al. Recruitment of seedlings versus ramets as affected by pasture degradation in alpine meadows and the implications for ecological restoration. Plant Ecol Divers. 2015;8(4):547-557. 
38. Shang ZH, Deng B, Ding LM, Ren GH, Xin GS, Liu ZY, et al. The effect of three years of fencing enclosure on soil seed banks and the relationship with above-ground vegetation of degraded alpine grasslands of the Tibetan plateau. Plant Soil. 2013;364:229-244.

39. Gao XX, Dong SK, Xu YD, Wu SN, Wu X, Zhang X, et al. Resilience of revegetated grassland for restoring severely degraded alpine meadows is driven by plant and soil quality along recovery time: $A$ case study from the Three-river Headwater Area of Qinghai-Tibetan Plateau. Agric Ecosyst Environ. 2019;279:169-177.

40. Shang ZH, Ma YS, Long RJ, Ding LM. Effect of fencing, artificial-seeding and abandonment on vegetation composition and dynamics of 'black soil land' in the headwaters of the Yangtze and the Yellow Rivers (HAYYR) of the Qinghai-Tibetan Plateau. Land Degrad Dev. 2008;19(5):554-563.

41. Franklin RB, Mills AL. Multi-scale variation in spatial heterogeneity for microbial community structure in an eastern Virginia agricultural field. FEMS Microbiol Ecol. 2003;44(3):335-346.

42. Wang SP, Duan JC, Xu GP, Wang YF, Zhang ZH, Rui YC, et al. Effects of warming and grazing on soil $N$ availability, species composition, and ANPP in an alpine meadow. Ecology. 2012;93(11):23652376.

43. Edwards J, Johnson C, Santos-Medellín C, Lurie E, Podishetty NK, Bhatnagar S, et al. Structure, variation, and assembly of the root-associated microbiomes of rice. Proc Natl Acad Sci U S A. 2015;112(8):911-920.

44. Caporaso JG, Kuczynski J, Stombaugh J, Bittinger K, Bushman FD, Costello EK, et al. QIIME allows analysis of high-throughput community sequencing data. Nat Methods. 2010;7:335-336.

45. Nair A, Ngouajio M. Soil microbial biomass, functional microbial diversity, and nematode community structure as affected by cover crops and compost in an organic vegetable production system. Appl Soil Ecol. 2012;58:45-55.

46. Shannon P, Markiel A, Ozier O, Baliga NS, Wang JT, Ramage D, et al. Cytoscape: a software environment for integrated models of biomolecular interaction networks. Genome Res. 2003;13(11):2498-2504.

47. Langille MGI, Zaneveld J, Caporaso JG, McDonald D, Knights D, Reyes JA, et al. Predictive functional profiling of microbial communities using 16S rRNA marker gene sequences. Nat Biotechnol. 2013;31(9):814-821.

48. Che RX, Wang YF, Li KX, Xu ZH, Hu JM, Wang F, et al. Degraded patch formation significantly changed microbial community composition in alpine meadow soils. Soil Tillage Res. 2019;195:104426.

49. Fang CW, Radosevich M, Fuhrmann JJ. Characterization of rhizosphere microbial community structure in five similar grass species using FAME and BIOLOG analyses. Soil Biol Biochem. 2001;33(4):679-682.

50. Shi SJ, Nuccio EE, Shi ZJ, He ZL, Zhou JZ, Firestone MK. The interconnected rhizosphere: high network complexity dominates rhizosphere assemblages. Ecol Lett. 2016;19(8):926-936. 
51. Zhalnina K, Louie KB, Hao Z, Mansoori N, da Rocha UN, Shi SJ, et al. Dynamic root exudate chemistry and microbial substrate preferences drive patterns in rhizosphere microbial community assembly. Nat Microbiol. 2018;3(4):470-480.

52. Zhou H, Zhang DG, Jiang ZH, Sun P, Xiao HL, Wu YX, et al. Changes in the soil microbial communities of alpine steppe at Qinghai-Tibetan Plateau under different degradation levels. Sci Total Environ. 2019;651:2281-2291.

53. Wagg C, Schlaeppi K, Banerjee S, Kuramae EE, van der Heijden, MGA. Fungal-bacterial diversity and microbiome complexity predict ecosystem functioning. Nat Commun. 2019;10(1):4841.

54. Thiergart T, Durán P, Ellis T, Vannier N, Garrido-Oter R, Kemen E, et al. Root microbiota assembly and adaptive differentiation among European Arabidopsis Nat Ecol Evol. 2020;4(1):122-131.

55. Trivedi P, Leach JE, Tringe SG, Sa T, Singh BK. Plant-microbiome interactions: from community assembly to plant health. Nat. Rev. Microbiol. 2020;18:607-621.

56. Harbort CJ, Hashimoto M, Inoue H, Niu YL, Guan R, Rombolà AD, et al. Root-secreted coumarins and the microbiota interact to improve iron nutrition in Arabidopsis. Cell Host Microbe. 2020;28:1-13.

57. Fierer N, Bradford MA, Jackson RB. Toward an ecological classification of soil bacteria. Ecology. 2007;88(6):1354-1364.

58. Kuske CR, Ticknor LO, Miller ME, Dunbar JM, Davis JA, Barns SM, et al. Comparison of soil bacterial communities in rhizospheres of three plant species and the interspaces in an arid grassland. Appl Environ Microbiol. 2002;68(4):1854-1863.

59. Haichar FEZ, Marol C, Berge O, Rangel-Castro JI, Prosser JI, Balesdent J, et al. Plant host habitat and root exudates shape soil bacterial community structure. ISME J. 2008;2(12):1221-1230.

60. Knox OGG, Gupta VVSR, Lardner R. Field evaluation of the effects of cotton variety and GM status on rhizosphere microbial diversity and function in Australian soils. Soil Res. 2014;52(2):203-215.

61. Richard HREE. 2011. DNA barcoding of Pedicularis (Orobanchaceae): Evaluating four universal barcode loci in a large and hemiparasitic genus. J Syst Evol. 2011;(05):49-61.

62. Singh HP, Batish DR, Kohli RK. Autotoxicity: Concept, organisms, and ecological significance. Crit Rev Plant Sci. 1999;18(6):757-772.

63. Ni LX, Acharya K, Hao XY, Li SY. Isolation and identification of an anti-algal compound from Artemisia annua and mechanisms of inhibitory effect on algae. Chemosphere. 2012;88:1051-1057.

64. Miller DA. Allelopathy in forage crop systems. Agron J. 1996;88(6):854-859.

65. Berendsen RL, Pieterse CMJ, Bakker PAHM. The rhizosphere microbiome and plant health. Trends Plant Sci. 2012;17(8):478-486.

66. Bulgarelli D, Schlaeppi K, Spaepen S, Van Themaat EVL, Schulze-Lefert P. Structure and functions of the bacterial microbiota of plants. Annu. Rev. Plant Biol. 2013;64:807-838.

67. Bakker, P.A.H.M., Berendsen, R.L., Doornbos, R.F., Wintermans, P.C.A., Pieterse, C.M.J. The rhizosphere revisited: root microbiomics. Front Plant Sci. 2013;4:165. 
68. Liu LL, Huang XQ, Zhang JB, Cai ZC, Jiang K, Chang YY. Deciphering the relative importance of soil and plant traits on the development of rhizosphere microbial communities. Soil Biol Biochem. 2020;148:107909.

69. Ladygina N, Hedlund K. Plant species influence microbial diversity and carbon allocation in the rhizosphere. Soil Biol Biochem. 2010;42:162-168.

70. Yuan J, Zhao J, Wen T, Zhao ML, Li R, Goossens P, et al. Root exudates drive the soil-borne legacy of aboveground pathogen infection. Microbiome. 2018;6(1):1-12.

71. Stringlis IA, Yu K, Feussner K, de Jonge R, Bentum SV, Verl MCV, et al. MYB72-dependent coumarin exudation shapes root microbiome assembly to promote plant health. Proc Natl Acad Sci U S A. 2018.115(22):5213-5222.

72. Voges MJ, Bai Y, Schulze-Lefert P, Sattely ES. Plant-derived coumarins shape the composition of an Arabidopsis synthetic root microbiome. Proc Natl Acad Sci U S A. 2019;116(25):12558-12565.

73. Weisskopf L, Abou-Mansour E, Fromin N, Tomasi N, Santelia D, Edelkott I, et al. White lupin has developed a complex strategy to limit microbial degradation of secreted citrate required for phosphate acquisition. Plant Cell Environ. 2006;29(5):919-927.

74. Hermans SM, Buckley HL, Case BS, Curran-Cournane F, Taylor M, Lear G. Using soil bacterial communities to predict physico-chemical variables and soil quality. Microbiome. 2020;8(1):1-13.

75. Chaparro JMC, Badri DV, Vivanco JM. Rhizosphere microbiome assemblage is affected by plant development. ISME J. 2014;8(4):790-803.

76. Hassan S, Mathesius U. The role of flavonoids in root-rhizosphere signalling: opportunities and challenges for improving plant-microbe interactions. J Exp Bot. 2012;63(9):3429-3444.

77. Daims H, Wagner M. Nitrospira. Trends Microbiol. 2018;26(5):462-463.

78. Zhang CB, Liu WL, Luo B, Guan M, Wang J, Ge Y, et al. Spartina alterniflora invasion impacts denitrifying community diversity and functioning in marsh soils. Geoderma. 2020;375:114456.

79. Ehrt S, Schnappinger D. Mycobacterium tuberculosis virulence: lipids inside and out. Nat Med. 2007;13(3):284-285.

80. Zhou J, Deng Y, Luo F, He ZL, Tu QC, Zhi XY. Functional molecular ecological networks. MBio. 2010;1(4):e00169-10.

81. Deng Y, Jiang YH, Yang YF, He ZL, Zhou JZ. Molecular ecological network analyses. BMC Bioinformatics. 2012;13(1):113.

82. Paine RT. A Conversation on refining the concept of keystone species. Conserv Biol. 1995;9(4):962964.

83. Power ME, Tilman D, Estes JA, Menge BA, Bond WJ, Mills LS, et al. Challenges in the quest for keystones. Bioscience. 1996;46:609-620.

84. Olesen JM, Bascompte J, Dupont YL, Jordano P. The modularity of pollination networks. Proc Natl Acad Sci U S A. 2007;104(50):19891-19896. 


\section{Figures}
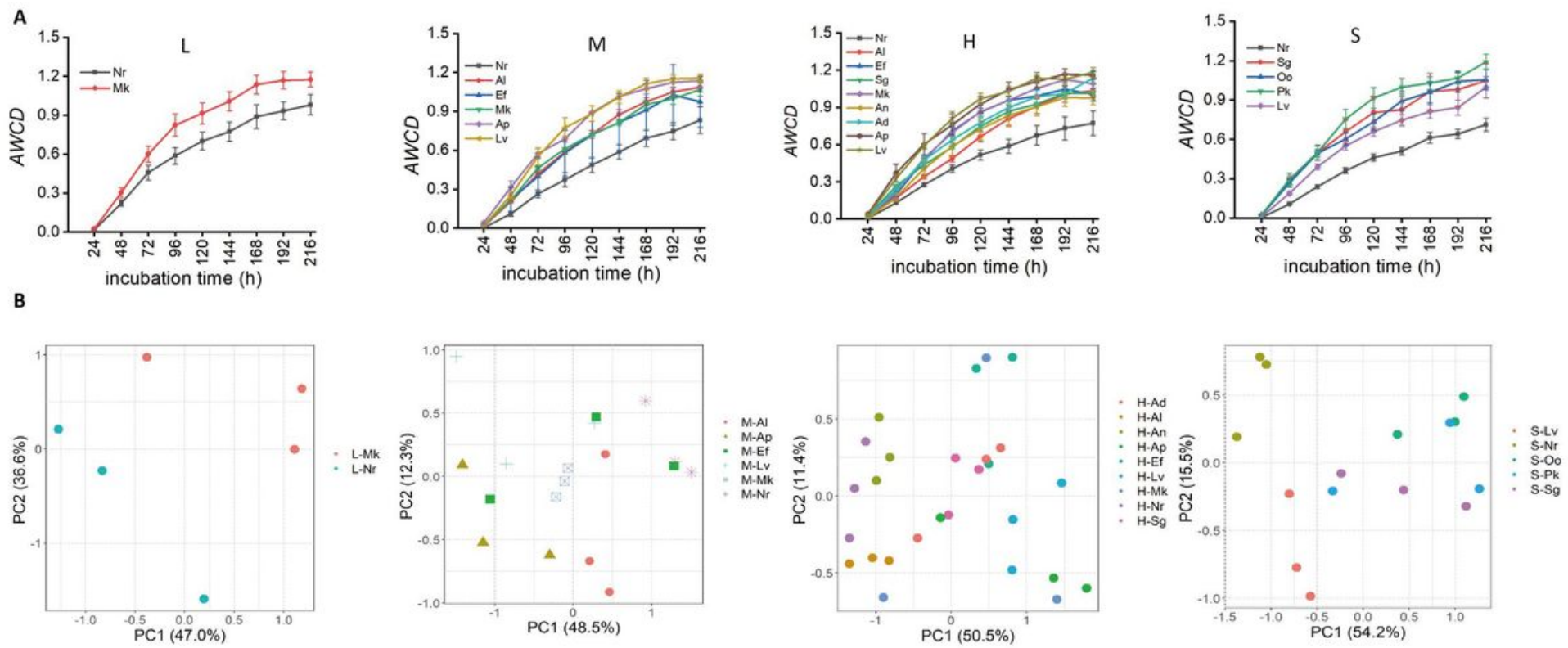

\section{Figure 1}

AWCD growth curve of soil microbes in different levels of grassland degradation $(A)$ and Principal component analysis (PCA) of carbon source utilization of soil microbial communities (B). L, lightly degraded native grassland; $M$, moderately degraded native grassland; $H$, heavily degraded native grassland; S, degraded sown grassland. Nr, the bulk soil, namely non-rhizosphere soil. Al, Ajuga lupulina; Ef, Euphorbia fischeriana; Sg, Sphallerocarpus gracilis; Oo, Oxytropis ochrocephala; Mk, Morina kokonorica; Pk, Pedicularis kansuensis; An, Artemisia nanschanica; Ad, Artemisia dubia; Ap, Aconitum pendulum; Lv, Ligularia virgaurea. 


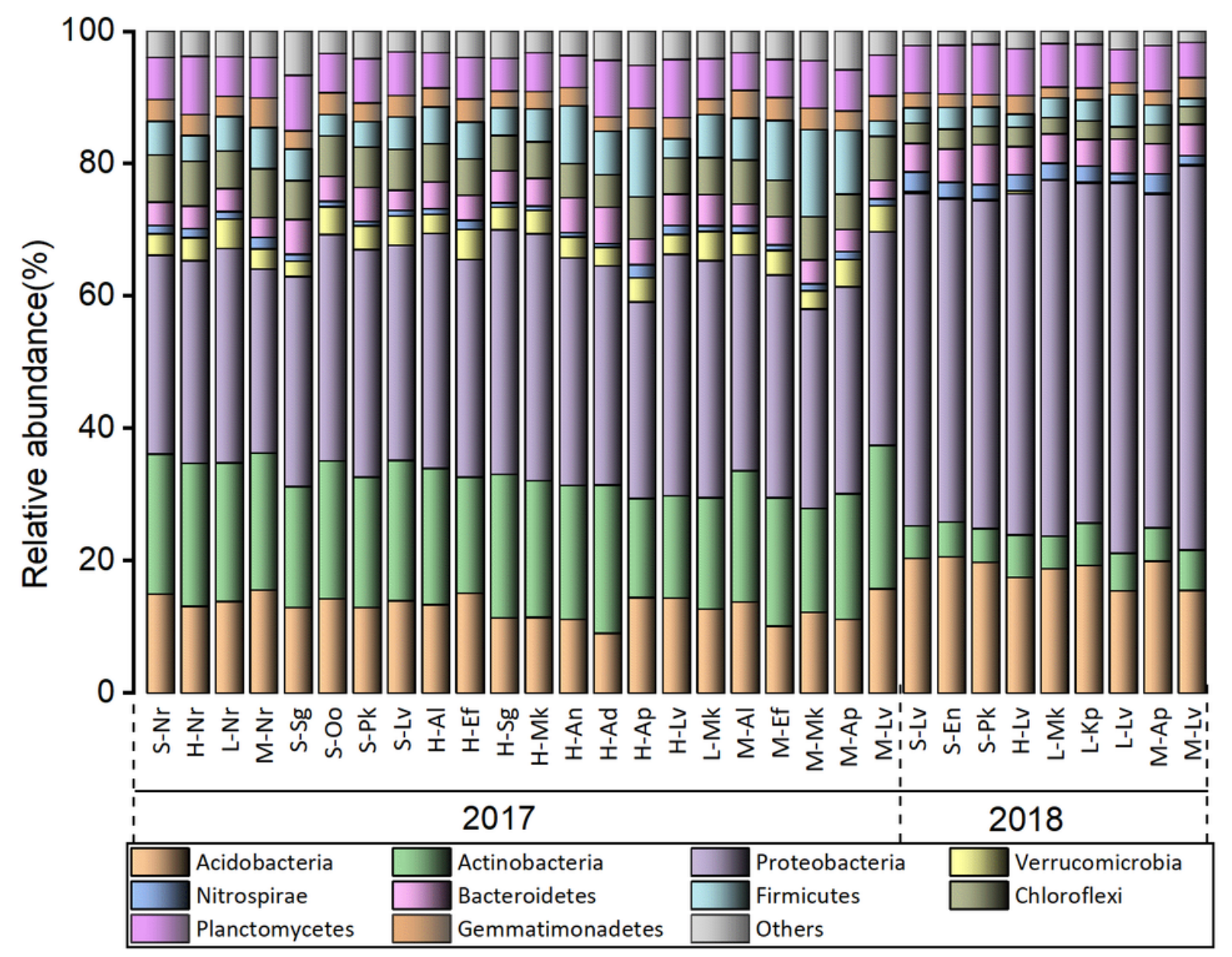

\section{Figure 2}

The relative abundance of phyla in the bacterial community. L, lightly degraded native grassland; $M$, moderately degraded native grassland; $\mathrm{H}$, heavily degraded native grassland; $\mathrm{S}$, degraded sown grassland. Nr, the bulk soil, namely non-rhizosphere soil. Al, Ajuga lupulina; Ef, Euphorbia fischeriana; Sg, Sphallerocarpus gracilis; Oo, Oxytropis ochrocephala; Mk, Morina kokonorica; Pk, Pedicularis kansuensis; An, Artemisia nanschanica; Ad, Artemisia dubia; Ap, Aconitum pendulum; Lv, Ligularia virgaurea; En, Elymus nutans; Kp, Kobresia pygmaea. 


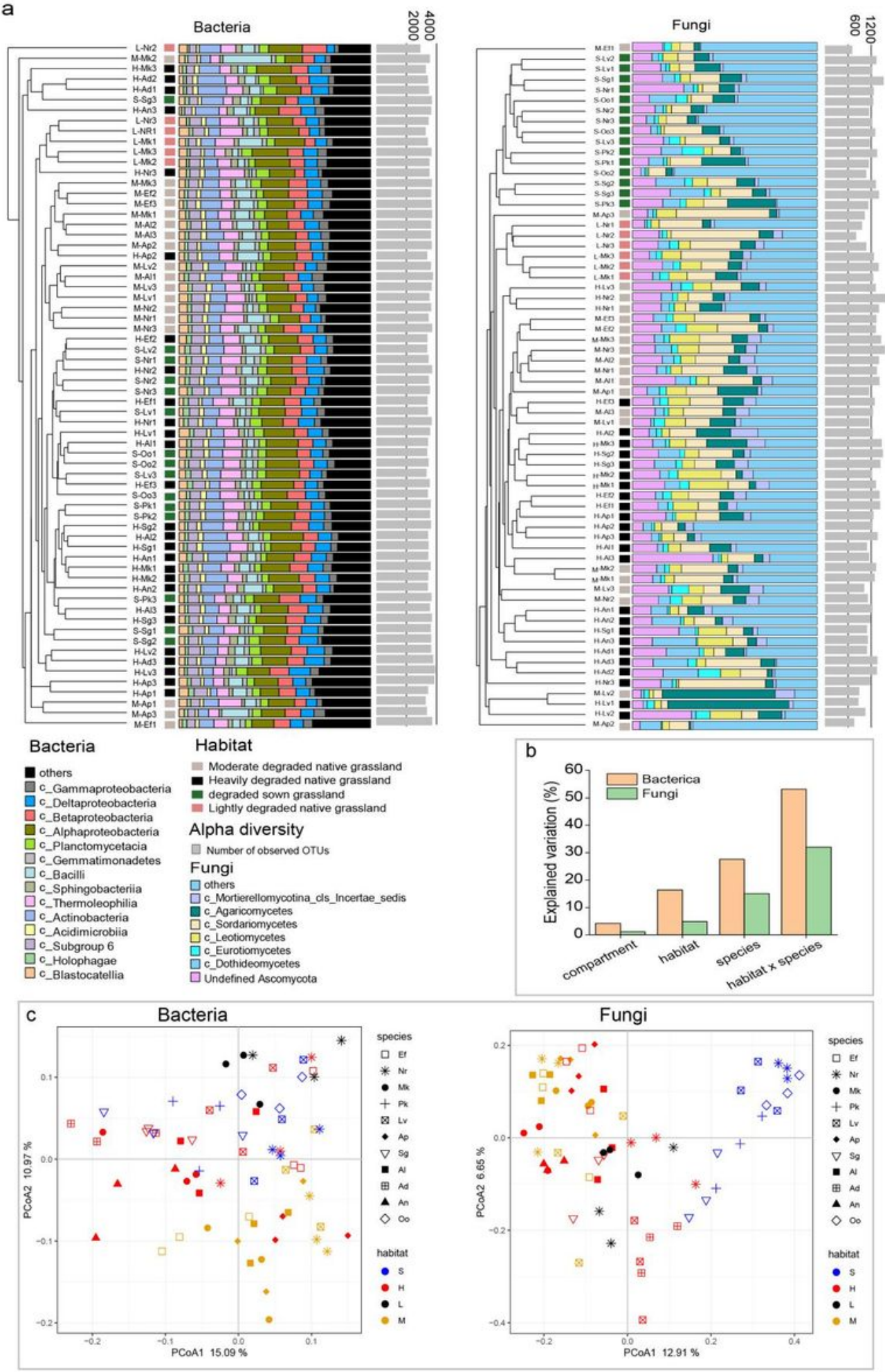

Figure 3

Microbial community structure and factors shaping the structure in 66 samples in 4 habitats. a, BrayCurtis similarity-based dendrogram showing average bacterial (left) and fungal (right) community composition. OTUs with relative abundance $>1 \%$ were considered. Habitats are indicated with coloured squares (pink: lightly degraded native grassland (L); gray: moderately degraded grassland (M); green: degraded sown grassland (S); black: heavily degraded native grassland $(\mathrm{H})$ ). For each sample, 
community composition with class level of bacteria and fungi are indicated with bar plots, and microbial a-diversity is represented with gray bars according to the number of observed OTUs. b, Effect of compartment, habitat, species and habitat $\times$ species on bacterial and fungal community composition. The explained variance for each factor is shown for bacteria and fungi based on PERMANOVA $(P<0.001$ in bacteria and $P>0.05$ in fungi). Compartments include bulk soil and rhizosphere. $c, P C o A$ based on Bray-Curtis distances between samples harvested across 66 samples in 4 habitats. Nr, the bulk soil, namely non-rhizosphere soil. Al, Ajuga lupulina; Ef, Euphorbia fischeriana; Sg, Sphallerocarpus gracilis; Oo, Oxytropis ochrocephala; Mk, Morina kokonorica; Pk, Pedicularis kansuensis; An, Artemisia nanschanica; Ad, Artemisia dubia; Ap, Aconitum pendulum; Lv, Ligularia virgaurea.
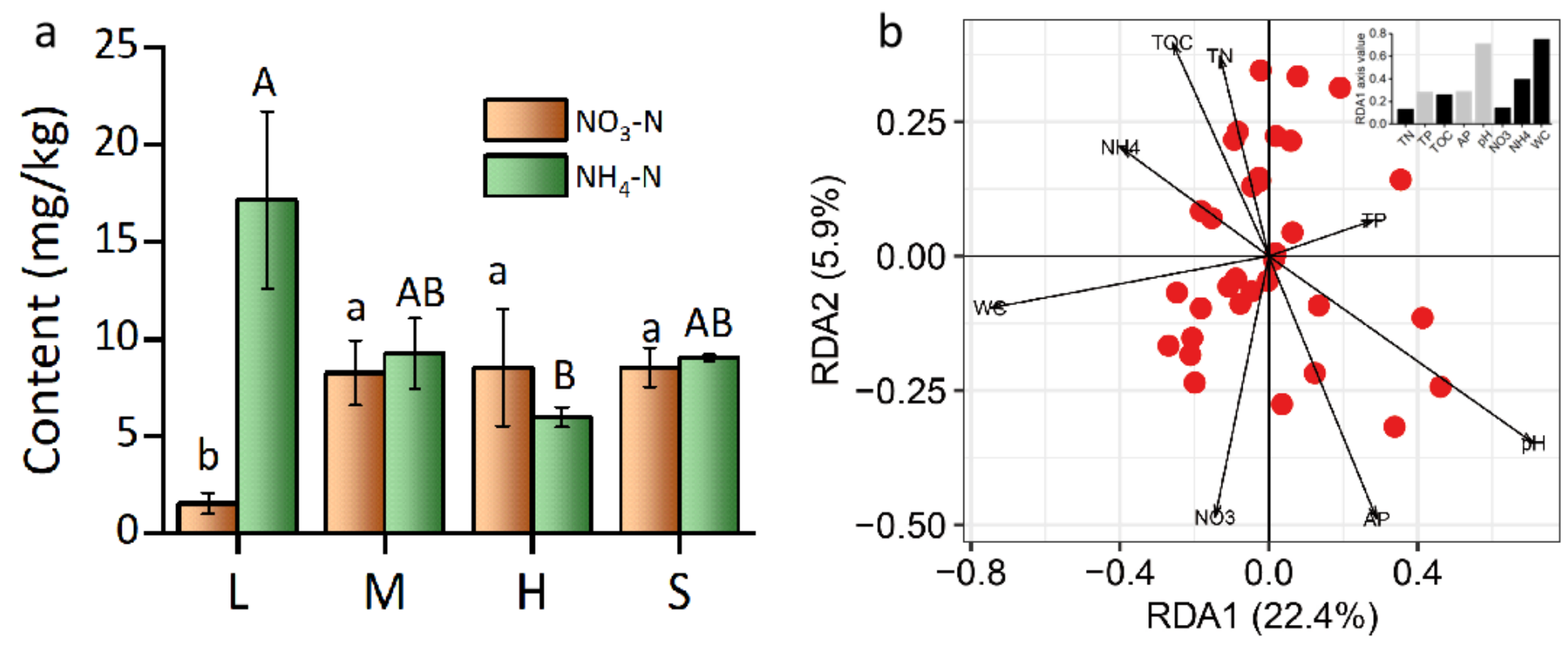

Figure 4

The content of NO3-N and NH4-N in bulk soil $(\mathrm{P}<0.05)(a)$. L, lightly degraded native grassland; $\mathrm{M}$, moderately degraded native grassland; $\mathrm{H}$, heavily degraded native grassland; $\mathrm{S}$, degraded sown grassland. $\mathrm{Nr}$, non-rhizosphere soil. Redundancy analysis (RDA) of the relationship between soil physical and chemical properties and the Bray-Curtis distances in bacterial communities (b). Dots indicate individual rhizospheres of poisonous plant species. The arrow lengths and directions correspond to the variance that could be explained by the individual soil physical and chemical properties. Insert: loadings (RDA axis values) for the individual soil physical and chemical properties $(P<0.05)$. Black and gray colors of the bars indicate negative and positive values, respectively. TN, total nitrogen; TP, total phosphorus; TOC, total organic carbon; AP, available phosphorus; NO3, nitrate nitrogen; NH4, ammonium nitrogen; WC, water content. 

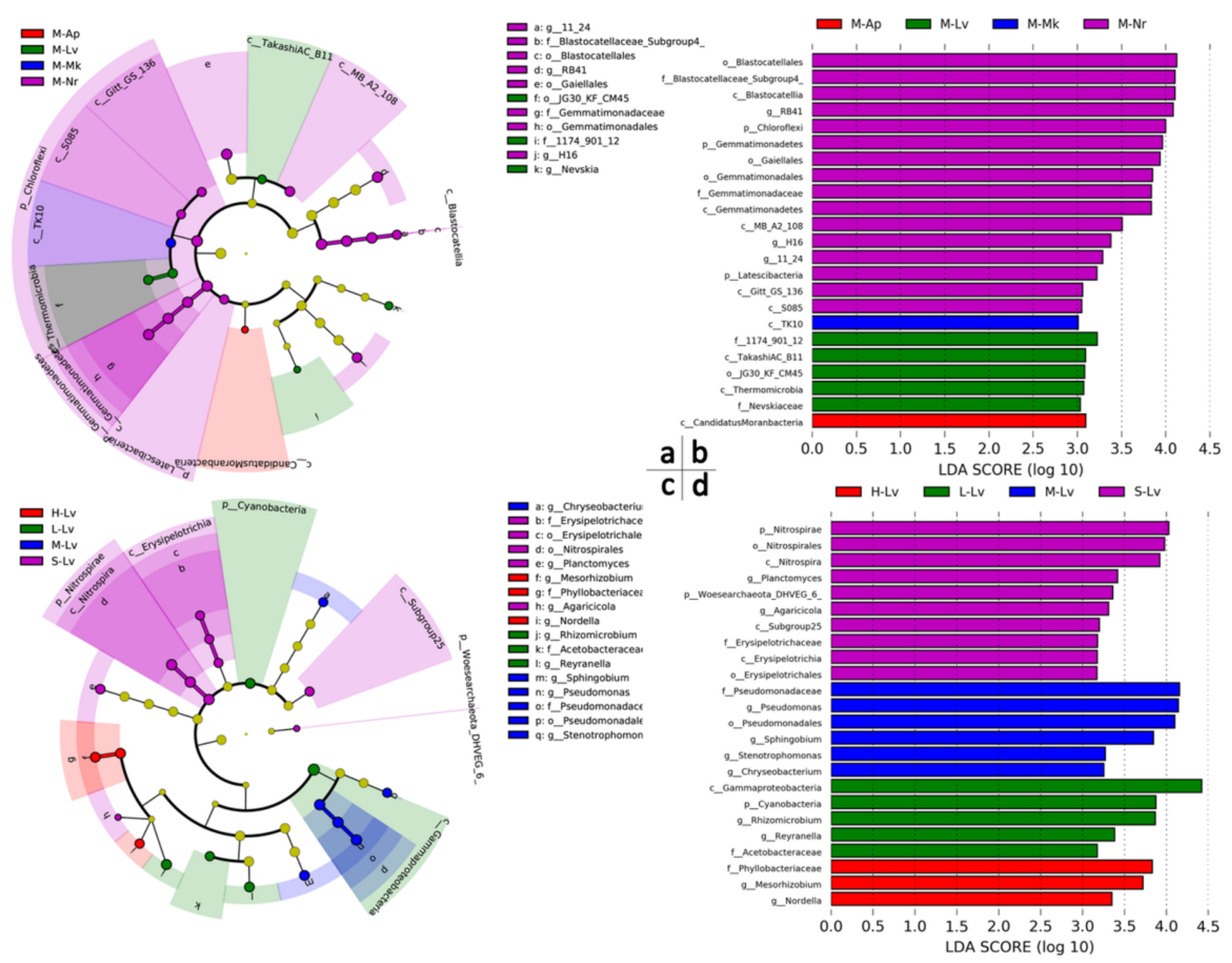

Figure 5

Lefse analysis of microbial abundance in moderately degraded native grassland (M) (a) and L. virgaurea in lightly degraded grassland (L), moderately degraded grassland $(M)$, heavily degraded grassland $(H)$, and degraded sown grassland (S) (c). b and d are the histograms of LDA scores computed for different abundant microbes among samples corresponding to a and c identified with a threshold value of 3.0. Nr, non-rhizosphere soil. Mk, Morina kokonorica; Pk, Pedicularis kansuensis; Lv, Ligularia virgaurea. 
a

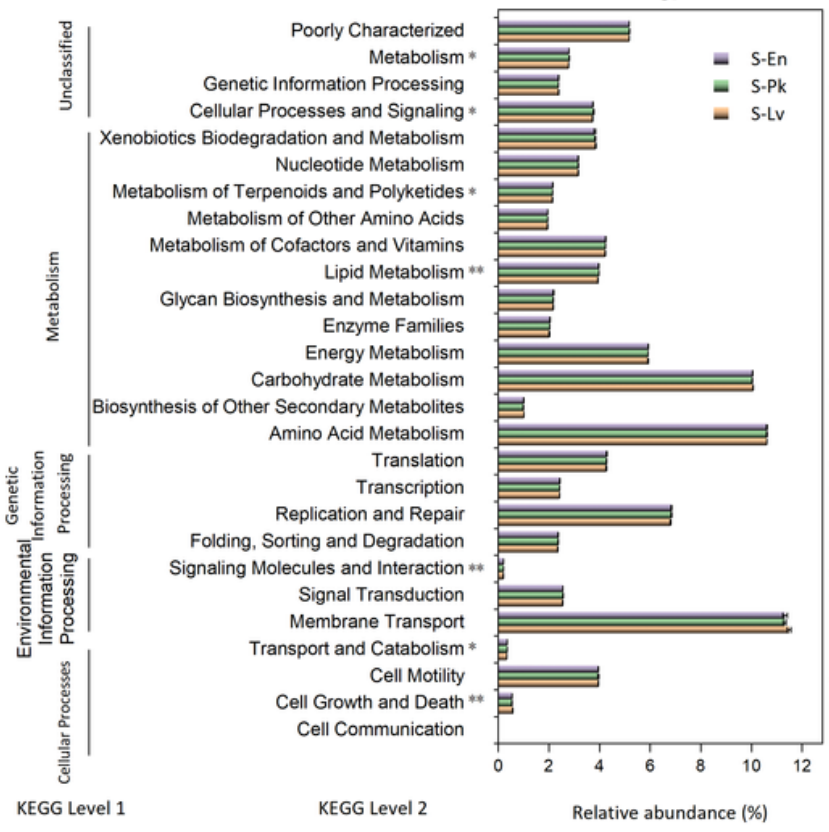

b

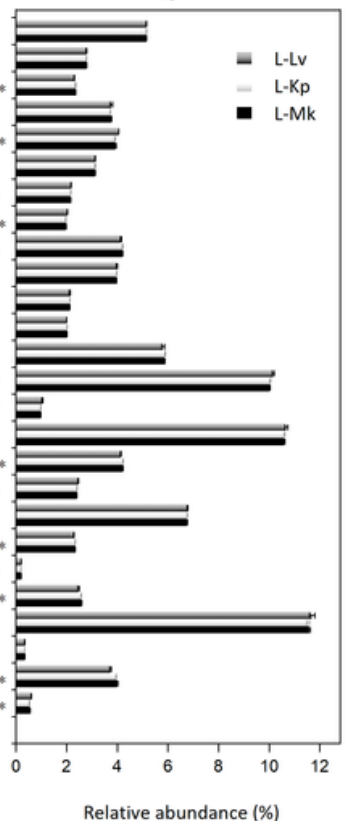

C

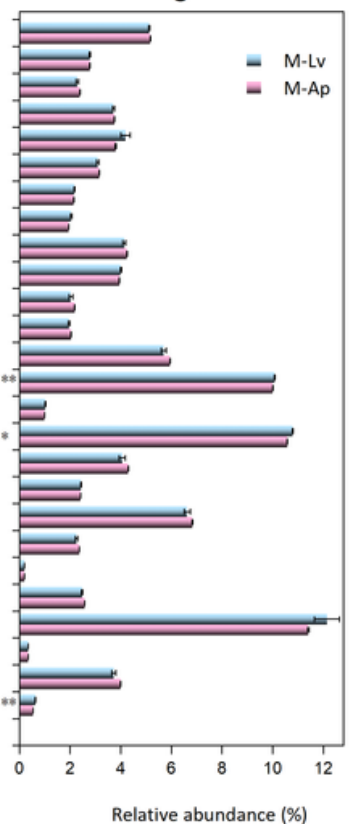

d

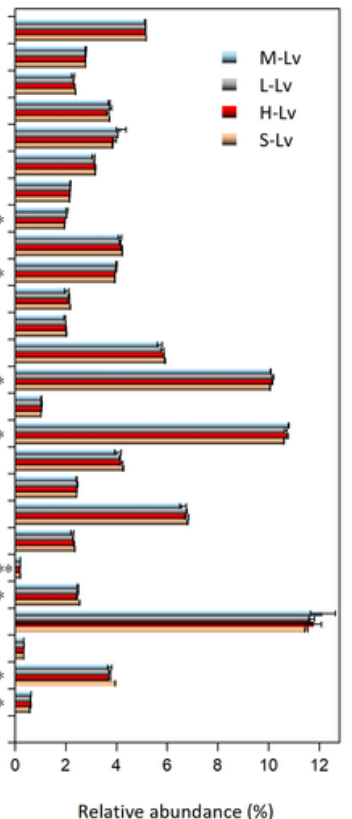

\section{Figure 6}

16s function prediction analysis. a, b, c are plant rhizosphere microorganisms in degraded sown grassland (S), lightly degraded grassland (L) and moderately degraded grassland (M). d, Ligularia virgaurea in four habitats. $\mathrm{H}$, heavily degraded grassland; Mk, Morina kokonorica; Pk, Pedicularis kansuensis; Ap, Aconitum pendulum; Lv, Ligularia virgaurea; En, Elymus nutans; Kp, Kobresia pygmaea. * and ** represent $P<0.05$ and $P<0.001$. 


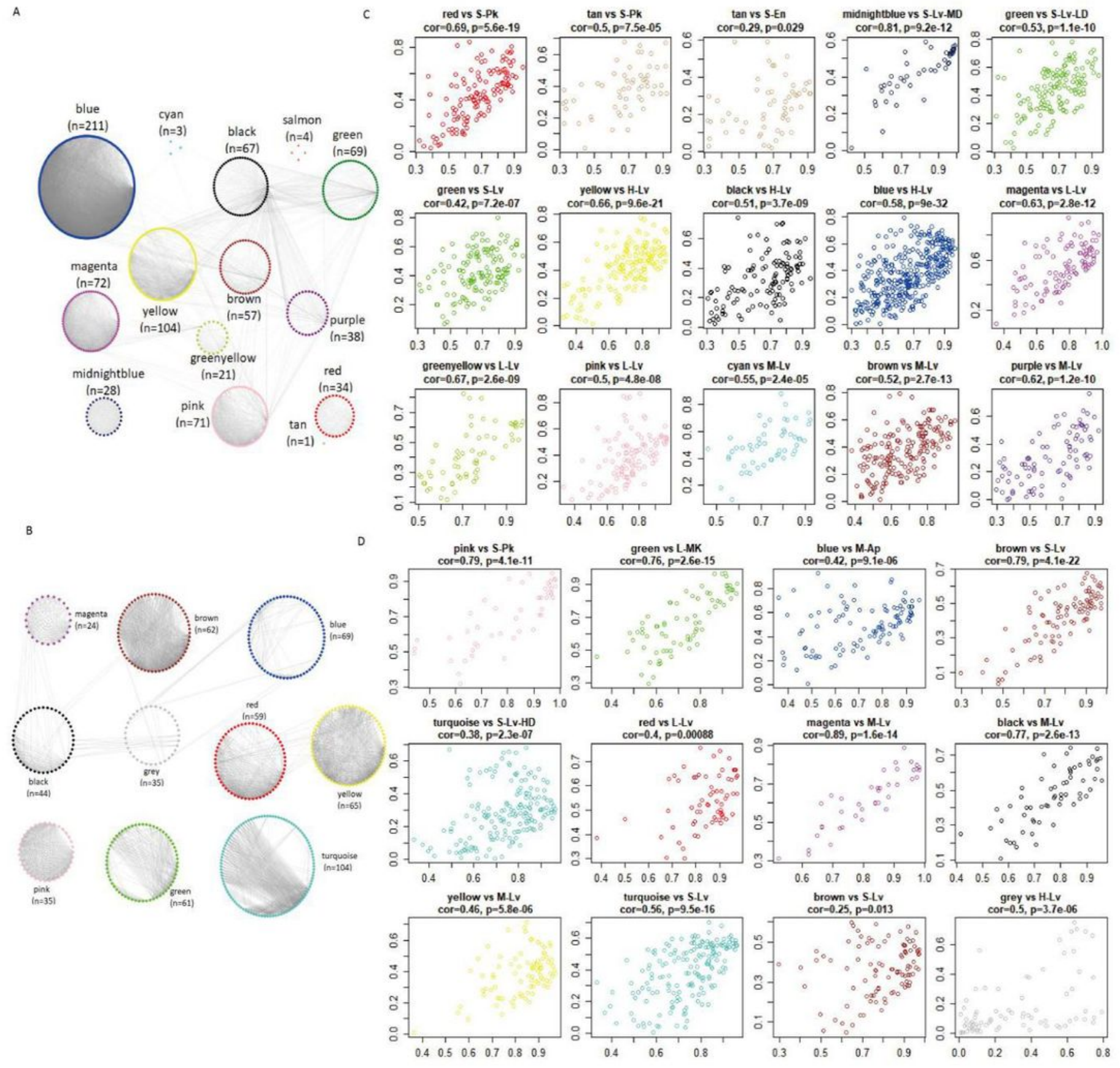

\section{Figure 7}

The networks of bacterial OTUs (A) and root exudation (B) in the rhizosphere of poisonous plant species (threshold $=0.2, \mathrm{P}<0.05 . \mathrm{n}$, number of OTUs in different color modules). Correlations between OTUs (C) or exudates (D) module enigengenes and plant species in each module. $L$, lightly degraded grassland; $M$, moderately degraded grassland; $\mathrm{H}$, heavily degraded grassland; $\mathrm{S}$, degraded sown grassland. Pk, Pedicularis kansuensis; En, Elymus nutans; Lv, Ligularia virgaurea; Mk, Morina kokonorica; Ap, Aconitum 
pendulum. LD and MD were the low and middle density of Ligularia virgaurea in degraded sown grassland, respectively.
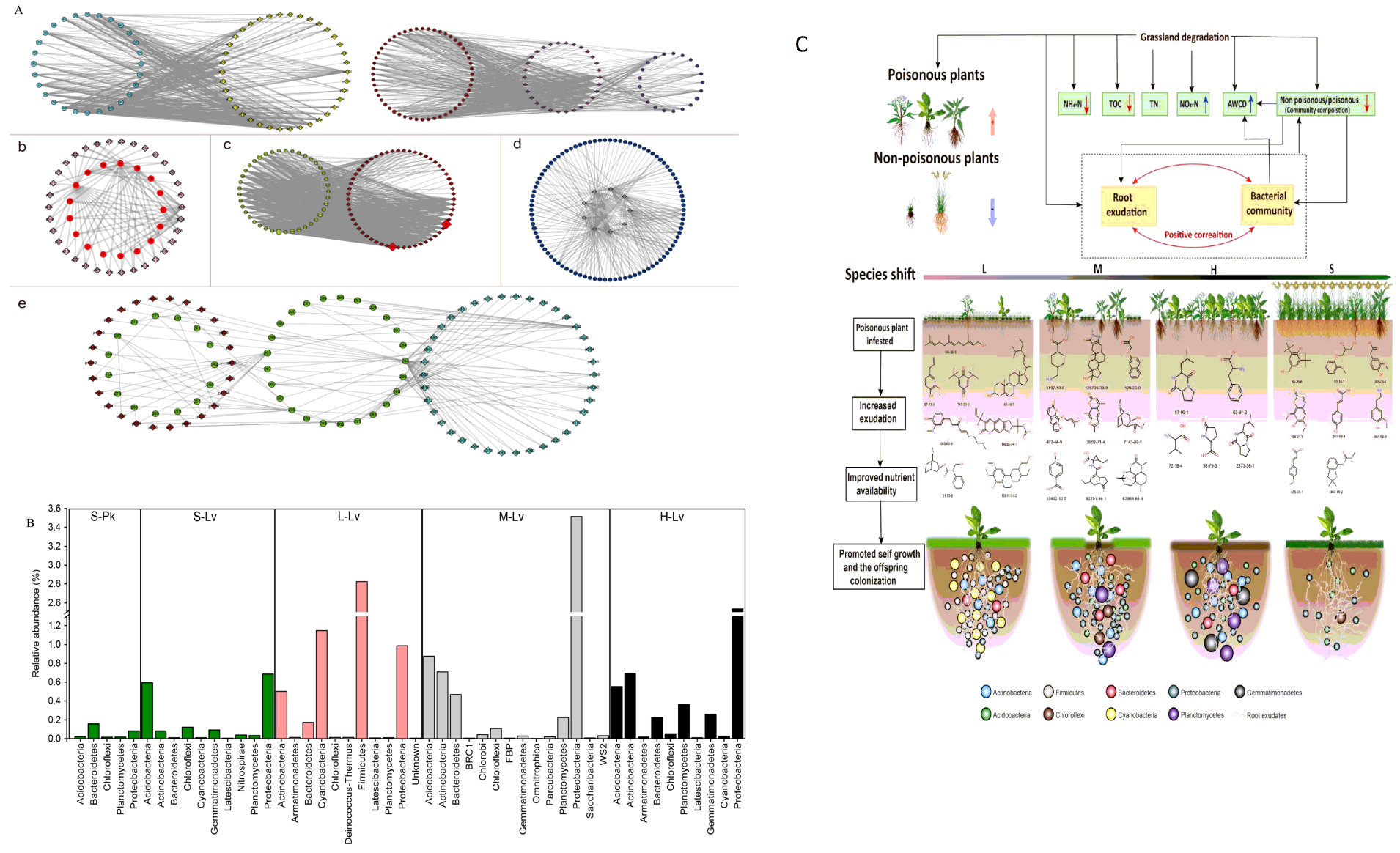

\section{Figure 8}

Network analysis of positive correlations between bacterial communities and root exudation modules ( $P$ $<0.05$ ) (A). Circles represent OTUs, diamonds represent root exudates and the colors correspond with module colors. For OTUs, the sizes of the shapes represent the relative abundance, for root exudates the relative content. a-e are the networks of M-Lv, S-Pk, L-Lv, H-Lv and S-Lv, respectively. The phyla of bacteria related significantly to root exudates (B). The histogram and colors represent relative abundance and habitat. pink: lightly degraded grassland (L); gray: moderately degraded grassland (M); green: degraded sown grassland (S); black: heavily degraded grassland. Poisonous plant root exudates and rhizosphere bacteria interactions in degraded grassland (C). 

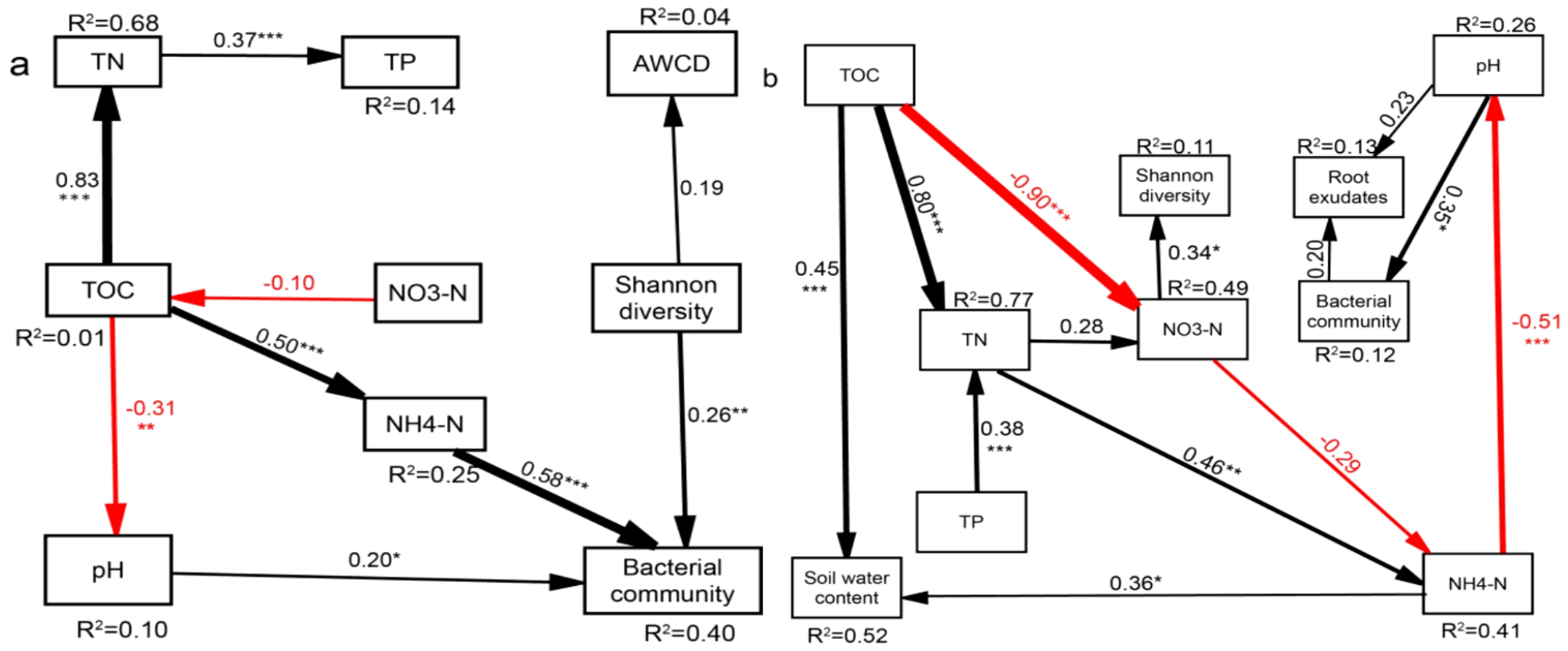

Figure 9

Structural equation modelling (SEM) depicting the relationships between soil properties, bacterial communities, Shannon diversity index and AWCD (a) and root exudates (b). The thickness of the arrows indicates the strength of the causal relationship, supplemented by a path coefficient. R2 values denote the amount of variance explained by the model for the response variables. Significance levels of each predictor are ${ }^{*} \mathrm{P}<0.05, * \star \mathrm{P}<0.01$ and $* \star \star \mathrm{P}<0.001$. SEM model fit were satisfactory $(\mathrm{a}, \chi 2 / \mathrm{df}=0.992, \mathrm{P}$ $=0.48 ;$ RMSEA=0.000; $b, \chi 2 / d f=0.679, P=0.91 ; R M S E A=0.000)$.

\section{Supplementary Files}

This is a list of supplementary files associated with this preprint. Click to download.

- Additionalfile1.docx

- Additionalfile2.xIsx 